\title{
El Bronce Final en el levante de la península Ibérica: bases arqueológicas y periodización
}

\section{Late Bronze Age in Eastern Iberian Peninsula: Archaeological Bases and Periodization}

\author{
Francisco Javier Jover Maestre*, Alberto Lorrio Alvarado**, \\ María de los Ángeles DíAz TenA*** \\ *Instituto Universitario de Investigación en Arqueología y Patrimonio Histórico (INAPH) \\ Universidad de Alicante \\ javier.jover@ua.es \\ **Instituto Universitario de Investigación en Arqueología y Patrimonio Histórico (INAPH) \\ Universidad de Alicante \\ alberto.lorrio@ua.es \\ ***Oxford Archaeology \\ Oxford \\ madiaztena@gmail.com
}

Recibido: 06-09-2015

Aceptado: 07-05-2016

\begin{abstract}
RESUMEN
Las investigaciones sobre el tránsito del II al I milenio cal BC en las tierras del Levante de la península Ibérica cuentan con una larga tradición investigadora. Sin embargo, las posibilidades de profundizar en el proceso histórico se han visto limitadas por la escasez de secuencias estratigráficas bien contextualizadas y datadas. Por esta razón, los diferentes estudios que se han venido publicando hasta hace poco han seguido las propuestas de periodización desarrolladas en zonas próximas, especialmente el Sudeste y el Nordeste peninsular. Con el desarrollo de las excavaciones arqueológicas en diversos asentamientos, el aumento del número de dataciones y la realización de diversos estudios en los últimos años, las perspectivas de investigación sobre el Bronce final en el Levante comienza a variar sustancialmente, estando ya en condiciones de proponer, una nueva periodización con la que profundizar en los cambios que acontecieron entre el 1500 y el 725 cal $B C$.
\end{abstract}

Palabras Clave: Bronce Final, Periodización, patrón de asentamiento, dataciones absolutas, Levante penínsular.

\begin{abstract}
Research surrounding the transition from II to I millennium cal BC in Eastern Iberian Peninsula has a large and extensive tradition of investigation. However, the chances to do research on this historical process have been limited by the lack of a well contextualized and dated stratigraphic sequence. For this reason, recent studies in this topic have followed the periodic proposals which were developed in closer regions and areas, especially in the South East and North East of the Peninsula. The investigation perspective about the Late Bronze in Eastern Iberian has however now improved, with the development of several archaeological investigations, the increase in the number of sites being dated and more recent studies into the region helping to bring about this change. As such, it is now in the correct state to be able to propose a new periodization and delve into the changes which occurred in the transition between 1500 and $725 \mathrm{cal} B C$.
\end{abstract}

Keywords: Later Bronze Age, Periodization, Settlement Patterns, Absolute Dating, Eastern Peninsula Iberica.

Sumario: 1. Introducción. 2. El problema central: la continuidad del área cultural del "Bronce Valenciano". 3. Las nuevas bases estratigráficas y radiocarbónicas. 4. Hacia una nueva propuesta de periodización. 5. A modo de conclusión. 


\section{Introducción}

Han transcurrido veinte años desde la publicación de un importante trabajo de síntesis sobre las fases arqueológicas previas al desarrollo de las sociedades iberas en las tierras valencianas (Mata, Martí e Iborra 1994/96), en el que se mostraba el proceso de investigación sobre el periodo comprendido entre el Bronce tardío -o reciente- y el Hierro antiguo ${ }^{1}$. Las autoras, además de destacar las propuestas de periodización previas de Gil-Mascarell y Aranegui (1981) y González Prats (1985a; 1992), intentaban dar respuesta al Bronce final, un periodo de amplio desarrollo temporal donde tenían cabida un considerable número de yacimientos, con un patrón de asentamiento muy variado y con una cultura material, en especial cerámica a mano, de muy variada tipología y técnicas decorativas.

Sin embargo, en aquellos momentos, las excavaciones arqueológicas en extensión eran muy limitadas y las dataciones absolutas enormemente escasas. Por estas razones no debe extrañar las dificultades que existían para adscribir cronológicamente cualquier yacimiento reconocido en prospecciones e incluso objeto de sondeos arqueológicos, y que todavía se planteara la posible continuidad cultural del "Bronce Valenciano", propuesto décadas antes por Tarradell $(1963 ; 1969)$.

Con el presente artículo, pretendemos señalar alguno de los problemas que, a nuestro entender, más han influido en el escaso avance de los estudios sobre el Bronce final en las tierras valencianas y mostrar algunos de los progresos que se han dado en las últimas dos décadas. Dicho análisis servirá para exponer una nueva propuesta de periodización, a pesar de que algunos de los problemas señalados por los investigadores que han tratado el tema siguen persistiendo.

\section{El problema central: la continuidad del área cultural del "Bronce Valenciano"}

Uno de los problemas más importantes que ha tenido el desarrollo de las investigaciones de la etapa final de la Edad del Bronce en las tierras valencianas ha sido la atribución de una pretendida continuidad cultural del llamado "Bronce Valenciano" hasta la iberización (Tarradell 1963; 1969). Las propuestas de P. Bosch Gimpera (1932) habían consolidado la idea de que, desde el Neolítico, en el solar peninsular existía un fuerte substrato poblacional, culturalmente diver- sificado, que aunque pudiera recibir influencias mediterráneas o de otros lugares, persistiría hasta la llegada masiva de pobladores centroeuropeos, ya en el primer milenio a.C. (Bosch 1932: 457). Esta pretendida invasión marcaba el comienzo de la Edad del Hierro, caracterizada por el rito funerario de la incineración y por la presencia de nuevas formas cerámicas, principalmente urnas acanaladas. Por este motivo, no es de extrañar que ante la práctica ausencia de necrópolis de incineración y la escasa incidencia de las cerámicas acanaladas en los registros materiales de las tierras valencianas, Tarradell (1969: 25-26) propusiera, como hipótesis, la continuidad cultural del Bronce Valenciano hasta prácticamente el siglo V a.C. Solamente para los territorios más septentrionales del área valenciana se apreciaba la presencia de algunos elementos atribuidos al ámbito hallstáttico, que hacían suponer que esta área cultural podía haber pasado por diversas fases, pero siempre con matices secundarios.

Años más tarde, Llobregat (1975) se planteaba una mayor antigüedad para la Edad del Bronce así como una más clara presencia de estratos y materiales infrapuestos en poblados "ibéricos antiguos", casos de El Puig (Alcoi), Los Villares (Caudete de las Fuentes) y la Illeta dels Banyets (El Campello). De ahí que propusiera una primera Edad del Hierro de tipo céltico, limitada a yacimientos del área castellonense y una facies de tipo no céltica, representada por materiales de perduración del Bronce Valenciano, entre los que se podrían haber infiltrado algunas cerámicas decoradas de tipo exciso o impreso, presentes en yacimientos mucho más meridionales como $\mathrm{Ca}$ bezo Redondo o la Illeta dels Banyets (Llobregat 1975: 132-133), vislumbrando el influjo orientalizante en yacimientos como Los Saladares (Orihuela) (Arteaga y Serna 1973) y Vinarragell (Burriana) (Mesado 1974), que proporcionaban las primeras secuencias estratigráficas para buena parte de la primera mitad del I milenio a.C. Con todo, para Llobregat resultaba "harto discutible" la posibilidad de una influencia directa de los colonizadores fenicios, apuntando más bien "al impacto de reflejo de las mismas colonizaciones en tierras limítrofes, sobre todo para el sur de la región", considerando que este reflejo orientalizante alcanzaría igualmente los niveles protohistóricos más antiguos de La Alcudia de Elche (Llobregat 1975: 133-135).

A las excavaciones en Los Saladares (Arteaga y Serna 1973; 1975; 1979; Arteaga 1982) y Vinarragell (Mesado, 1974; Mesado y Arteaga, 1979), 
se añadirían las registradas en Penya Negra (Crevillent), primero con un sondeo en 1973, y entre 1976 y 1987 con excavaciones sistemáticas, que entre los años 1988 y 1991 se centrarían en el cementerio de Les Moreres, directamente vinculado al asentamiento crevillentino (González Prats 1983; 1990; etc.). Como ha destacado González Prats (1992: 139), los yacimientos de Los Saladares, Vinarragell y Penya Negra venían a confirmar de forma clara la existencia de un Bronce final y un Hierro antiguo como dos periodos bien caracterizados previos al desarrollo del mundo ibérico en la zona.

Con esta situación, a inicios de 1980 Gil-Mascarell y Aranegui (1981) publicaban un destacado ensayo sobre estas fases en el área levantina, partiendo de los trabajos de F. Molina (1978) para el Sureste y de G. Ruíz Zapatero (1978) sobre los Campos de Urnas en la península Ibérica. Gil-Mascarell (1981: 12) afirmaba que durante el Bronce final en el área levantina no se producía una transformación cultural generalizada debido a tres factores: la marginación cultural, un poblamiento valenciano poco permeable hacia nuevos asentamientos debido a su densidad demográfica, y una cultura del Bronce firmemente arraigada.

La aceptación de la perduración de una facies del "Bronce Valenciano" con algunas influencias, permanecería vigente hasta los primeros años de la siguiente década, a pesar de las reservas planteadas por autores como González Prats (1985a: 154; 1992: 139-140), para quien resultaba evidente la "desconexión estratigráfica", cuando no incluso topográfica, entre las ocupaciones del Bronce antiguo y pleno y las más recientes del Bronce final. Con todo, la propuesta de GilMascarell (1981) fue el punto de partida que permitió, años después, concretar el desarrollo cronológico de la cultura del Bronce Valenciano (Enguix y Martí 1988; Gil-Mascarell 1992), aunque su posible perduración siguió siendo objeto de discusión, como se evidenciaba en el trabajo de Mata, Martí e Iborra (1994/96: 210), donde al analizar el denominado Bronce tardío o reciente, todavía se consideraba como un tema candente la posible continuidad del Bronce medio, ante la escasa presencia de materiales de origen meseteño (Martí y Bernabeu 1992: 558). Con todo, lo que sí parecía evidente era la diferenciación entre el Bronce tardío y el Bronce final (Mata, Martí e Iborra 1994/96: 210), aunque, a pesar de los esfuerzos de concreción cronológica, el "Bronce Valenciano" continuaba siendo una entidad poco cuestionada como área cultural.
Habría que esperar a finales de la década de 1990 para comenzar a cuestionar su existencia en los términos que hasta ese momento habían sido planteados, así como para proponer una nueva periodización a partir de las pocas dataciones absolutas disponibles (Jover 1999). Respecto a la primera cuestión, era necesario explicar la diversidad de prácticas sociales que el registro arqueológico venía mostrando. De este modo, se propuso que en el territorio ocupado por el Bronce Valenciano, habrían existido diversas entidades sociales con un desarrollo temporal entre el 2100 y el $1500 \mathrm{cal} \mathrm{BC}$, y que esta diversidad sería la base del desarrollo cultural y social de momentos posteriores (Jover 1999: 92-97). Respecto, a la segunda, la agrupación de las escasas dataciones disponibles para los momentos finales del II e iniciales del I milenio cal $\mathrm{BC}$, únicamente permitían diferenciar entre una fase III o Bronce tardío, y una fase IV, asimilable al Bronce final I de Molina (1978), donde en sus momentos finales hacían su aparición las cerámicas acanaladas. Esta última fase precedería a otras nuevas fases, bien representadas en las tierras meridionales en asentamientos como Penya Negra (González Prats $1983 ; 1990 ; 2002)$, cuya secuencia sigue siendo el elemento esencial para la diferenciación de un Bronce final pleno -horizonte I de Penya Negrarespecto de la fase del Hierro antiguo u orientalizante - horizonte II de Penya Negra-.

\section{Las nuevas bases estratigráficas y radiocarbónicas}

Como ya hemos señalado, las propuestas de González Prats (1992) y Mata, Martí e Iborra (1994/96) vienen siendo los referentes básicos para el estudio del Bronce tardío y final en las tierras valencianas. En ambos trabajos se recogía el progreso efectuado en las investigaciones efectuadas en aquellos años. No en vano, la transferencia de competencias en materia patrimonial y arqueológica a la Conselleria de Cultura y Deportes de la Comunidad Valenciana, realizadas en 1983, había permitido afianzar el desarrollo de diversos proyectos de investigación. Durante los años ochenta y noventa del siglo $\mathrm{XX}, \mathrm{y}$ también durante la década siguiente, se vinieron desarrollando actuaciones de mayor o menor envergadura y duración en yacimientos como Mola d'Agres (Gil-Mascarell 1980; 1983, 1985; GilMascarell y Peña 1994; Peña et al., 1996; Grau et al., 2004), Les Raboses (Ripollés 2000), Pic 
dels Corbs (Barrachina 1999; 2009; 2012), Puntal dels Llops (De Pedro 2002; 2004: 47-49), Mas del Corral (Trelis 1992), Torrelló d'Onda (Gusi 1974; 1975), Orpesa la Vella (Gusi 1976; Gusi y Olària 1977; Barrachina y Gusi 2004; Gusi y Olària 2014), el Castellet o Castellet de Nadal (Oliver, García y Moraño 2005), Torrelló de Boverot (Clausell 2004), Cova d'en Pardo (Soler et al., 1999; Soler Díaz, 2012), Illeta dels Banyets (Llobregat 1986; Simón 1997; Soler Díaz 2006), Cabezo Redondo (Soler García 1987; Hernández 2001; 2009; 2012), Peña de Sax (Hernández y Pérez 2005), La Horna (Hernández 1994), Tabayá (Hernández y López 1992; Molina Mas 1999; Belmonte 2004) y Penya Negra-Les Moreres (González Prats 1983; 1990; 2002). Este conjunto de yacimientos, de diferentes tamaños y secuencias, a día de hoy constituyen el grueso para caracterizar la secuencia arqueológica en el ámbito regional.

Sin embargo, los resultados no han sido todo lo halagüeños que cabría haber esperado. Después de dos décadas de investigaciones resultan muy escasos los trabajos publicados en los que se haya detallado la secuencia estratigráfica y la interpretación de sus ocupaciones. Y, más aún, de muy pocos se cuenta con un número suficiente de dataciones absolutas que permitan concretar los periodos de ocupación de cada uno de ellos. La únicas series suficientemente amplia de dataciones absolutas se ha obtenido de Cabezo Redondo (Hernández 2009; 2012; Jover, López Padilla y García-Donato 2014), Orpesa la Vella (Gusi y Olària 2014) y Penya Negra (González Prats 1983; Gusi y Olària 1995), mientras que de otros pocos se han realizado más de cuatro dataciones -Pic dels Corbs, Torrelló de Boverot- aunque en su mayor parte, sobre muestras de vida larga y con desviaciones estándar demasiado amplias.

Siguen siendo de referencia obligada, no obstante, las excavaciones realizadas en Penya Negra (Crevillent) bajo la dirección González Prats (1977-78; 1983; 1990; 2002). Este asentamiento de grandes dimensiones, han mostrado una densa ocupación entre el siglo IX y el VI cal BC, dividida, de forma general, en dos grandes fases asimilables al Bronce final pleno y al Hierro antiguo, respectivamente. Aunque la superficie excavada ha sido considerable, su distribución en diferentes sectores muy alejados unos de otros no ha facilitado la posibilidad de profundizar en las características y evolución arquitectónica y urbanística en su globalidad. Los repertorios materiales de este asentamiento, en todas sus fases, están ampliamente publicados, por lo que no procede detenerse en ello. Ahora bien, sí creemos conveniente considerar las dificultades para concretar el inicio y final de cada una de las fases y contextos, a pesar de haberse realizado una decena de dataciones (González Prats 1983: 290-292; Gusi y Olària, 1995), dado que todas las muestras fueron realizadas sobre muestras de vida larga, algunas proporcionaron desviaciones estándar muy amplias y, otras, fechas muy alejadas del rango temporal al que corresponden los conjuntos arqueológicos de los que proceden. Con todo, la mayoría de las dataciones asimilables a Peña Negra I ofrecen un intervalo que permiten fechar este horizonte en pleno siglo IX cal BC (Torres 2008: 541), lo que no desentona con los datos proporcionados por el registro material (García Borja y Pérez 2012: 45).

Por otro lado, con independencia de la mayor o menor incidencia de las aportaciones efectuadas desde los proyectos de investigación emprendidos, cabe destacar la importancia que en el Levante peninsular viene teniendo el desarrollo de las actividades arqueológicas de salvamento. Es el caso de Sant Joaquim (Vizcaíno 2007), Costamar (Flors 2010), La Vital (García Borja et al., 2013), Caramoro II (González Prats y Ruiz 1992; García Borja et al., 2010), Barranc del Botx (García Borja et al., 2007) o El Botx-Grupintex (Trelis et al., 2004). De algunos de los yacimientos señalados contamos con una destacada información, no sólo estratigráfica, sino también dataciones sobre muestras de vida corta.

Con todo, las nuevas bases estratigráficas y cronológicas sin ser todavía lo suficientemente firmes por la falta de series radiométricas asociadas a los diversos momentos de construcción/ uso/abandono, unidas a la propuesta de clasificación y seriación de los repertorios cerámicos de buena parte de los yacimientos del área meridional valenciana (García Borja y Pérez 2012; Pérez Ballester 2014), permiten matizar la adscripción cronológica y relevancia que hace unos años se le otorgó a determinados yacimientos y a "objetostipo", y dar nuevos pasos hacia una periodización más cercana a la realidad en estudio.

\section{Hacia una nueva propuesta de periodización}

En el estado actual de las investigaciones, el uso de la estadística bayesiana en su aplicación a amplias series radiocarbónicas procedentes de con- 
textos arqueológicos, bien documentados estratigráficamente, constituye la mejor técnica para efectuar una peridiozación sobre bases sólidas, como se ha propuesto recientemente para momentos previos a los aquí tratados (Jover, López Padilla y García Donato 2014). Crear un sólido armazón cronológico requiere de unas buenas bases estratigráficas, asociadas a un número elevado de dataciones sobre muestras de vida de corta con una desviación estándar lo más baja posible.

Por desgracia, todavía estamos lejos de poder aplicar este tipo de técnicas al periodo temporal aquí en estudio ante la ausencia de amplias series radiocarbónicas sobre muestras de vida corta debidamente contextualizadas. Hasta el momento, el número de determinaciones radiométricas realizadas en tierras valencianas para el periodo cronológico situado entre el 1450 y el $725 \mathrm{cal} \mathrm{BC}$ alcanza la cincuentena, procedentes de un total de 24 yacimientos (Tabla 1) ${ }^{3}$. Los yacimientos con mayor número de dataciones son Cabezo Redon$\mathrm{do}^{4}$ con al menos nueve dataciones entre 1500 y 1250 cal BC, Penya Negra (González Prats 1983; Gusi y Olària 1995) con seis; Torrelló de Boverot (Clausell 2004) con cinco, además de Pic dels Corbs (Barrachina 2012) con cuatro y Orpesa la Vella ${ }^{5}$, Altet de Palau, El Negret, Costamar, Cova d'en Pardo, Solana del Castell de Xàtiva, El Molón y el Cabezo Pequeño del Estaño con dos. Ello supone que más de la mitad de los yacimientos con dataciones solamente cuentan con una muestra datada. Ahora bien, aunque de casi todas existe información sobre el tipos de muestra y procedencia, de muy pocas se han publicado datos sobre el carácter y la interpretación del contexto de procedencia. Si a esta situación añadimos que una buena parte de las mismas fueron efectuadas sobre muestras de vida larga; que las dataciones de vida corta están ampliamente repartidas en más de la mitad de los asentamientos y que una buena parte de las dataciones cuentan con una desviación estándar demasiado amplia, de poco serviría efectuar una propuesta de periodización que tuviese como base su análisis estadístico (Fig 1).

No obstante, lo que sí se puede considerar a partir de las dataciones y de la información estratigráfica y contextual publicada es que algunos asentamientos datados parecen abandonarse definitivamente o reestructurarse urbanísticamente de forma significativa en momentos muy próximos entre sí, constatándose al mismo tiempo, cambios destacados en el patrón de asentamiento o en algunos elementos de su materialidad. Si nos fijamos en la figura 2 en la que solamente se han

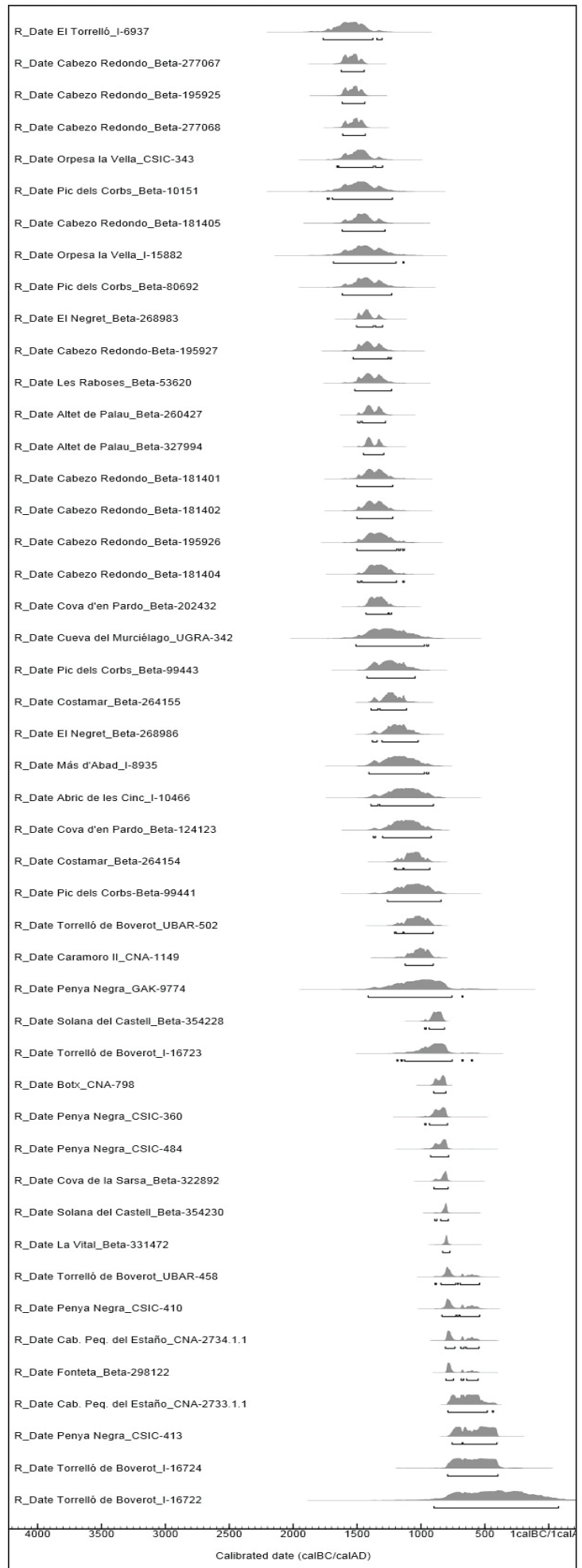

Figura 1. Gráfico con las curvas de calibración de las dataciones absolutas disponibles del ámbito geográfico en estudio. Programa OxCal v.4.2.3., según la curva atmosférica IntCal13 (Reimer et al. 2013). 


\begin{tabular}{|c|c|c|c|c|c|c|c|c|}
\hline YACIMIENTO & CONTEXTO & CONJUNTO & REFERENCIA & BP & CalBC 10 & $\mathrm{CalBC} 20$ & MUESTRA & BIBLIOGRAFIA \\
\hline El Torrelló & Hábitat en cerro & Nivel II-III_Q_-3 & $1-6937$ & $3265 \pm 90$ & $1635-1441$ & 1766-1304 & Carbón & Gusi 1974; Gusi y Olària 1995: 149 \\
\hline Cabezo Redondo & Hábitat en cerro & Espacio abierto. Estructura aislada & Beta-277067 & $3260 \pm 40$ & $1610-1499$ & $1624-1445$ & Triticum aestivum-durum & Hernández 2012:133, Fig. 18 \\
\hline Cabezo Redondo & Hábitat en cerro & Dep XXV. Junto peine marfil & Beta-195925 & $3250 \pm 40$ & $1608-1460$ & $1617-1440$ & Carbón & Hernández 2009:300; 2012: 133, Fig. 18 \\
\hline Cabezo Redondo & Hábitat en cerro & Dep. XXVIII. Construcción útimo pavimento & Beta-277068 & $3240 \pm 40$ & $1602-1450$ & $1612-1436$ & Hordeum vulgare & Hernández 2012:133, Fig. 18 \\
\hline Orpesa la Vella & Hábitat en cerro litoral & Q4. Nivel2 & CSIC-343 & $3210 \pm 70$ & $1606-1414$ & $1658-1301$ & Carbón & Gusi y Olària 1995: 148; 2014: 260, tabla 63 \\
\hline Pic dels Corbs & Hábitat en cerro & FIII. UE 1080. CE04. & Beta-10151 & $3200 \pm 100$ & $1614-1323$ & $1733-1224$ & Carbón & Barrachina 2009: 52, tabla 1; 2012: 133, tabla 5 \\
\hline Cabezo Redondo & Hábitat en cerro & Dep.XXV. Vasija & Beta-181405 & $3180 \pm 70$ & 1530-1321 & $1617-1282$ & Cereal & Hernández 2009: 299; 2012:133, Fig. 18 \\
\hline Orpesa la Vella & Hábitat en cerro litoral & QIX. NivelS & |-15882 & $3170 \pm 100$ & $1602-1297$ & 1686-1134 & Carbón & Gusi y Olària 1995: 148; 2014: 260, tabla 63 \\
\hline Pic dels Corbs & Hábitat en cerro & Fase III. UE 1071, nivel 5. & Beta-80692 & $3160 \pm 80$ & $1518-1303$ & $1616-1230$ & Carbón & Barrachina 2009: 52, tabla 1; $2012: 133$, tabla 5 \\
\hline El Negret & Hábitat en cerro & UE 1014. Abandono UH2 & Beta-268983 & $3150 \pm 40$ & $1495-1326$ & 1505-1301 & Diafisis mesomamifero & Barciela et al. $2012: 127$, fig. 24 \\
\hline Cabezo Redondo & Hábitat en cerro & Dep XXI. Uso de pavimento. & Beta-195927 & $3140 \pm 60$ & $1496-1306$ & 1531-1233 & Carbón & Hernández 2012:133, Fig. 18 \\
\hline Les Raboses & Hábitat en cerro & C-32. Nivel II & Beta-53620 & $3130 \pm 60$ & 1494-1302 & $1519-1231$ & Carbón & Ripollés 2000: 98 \\
\hline Altet de Palau & Hábitat en cerro & Estancia 3 & Beta-260427 & $3120 \pm 40$ & $1436-1304$ & $1496-1278$ & Hordeum vulgare & Garcia Borja y De Pedro 2013: 80 \\
\hline Altet de Palau & Hábitat en cerro & ámbito 20 calle central & Beta-327994 & $3120 \pm 30$ & $1432-1316$ & 1451-1291 & Hordeum vulgare & Garcia Borja y De Pedro 2013: 80 \\
\hline Cabezo Redondo & Hábitat en cerro & Dep. XIX. 4B & Beta-181401 & $3110 \pm 60$ & $1436-1289$ & 1501-1221 & Semillas & Hernández 2012:133, Fig. 18 \\
\hline Cabezo Redondo & Hábitat en cerro & Dep. XIX. $3^{\mathrm{a}}$ & Beta-181402 & $3110 \pm 60$ & $1436-1289$ & 1501-1221 & Semillas & Hernández 2012:133, Fig. 18 \\
\hline Cabezo Redondo & Hábitat en cerro & Dep. XXV. Cubeta superior & Beta-195926 & $3090 \pm 70$ & $1430-1264$ & 1502-1131 & Carbón & Hernández 2012:133, Fig. 18 \\
\hline Cabezo Redondo & Hábitat en cerro & Dep.XX. Nivel de incendio I. & Beta-181404 & $3080 \pm 60$ & $1414-1269$ & 1496-1132 & Carbón & Hernández 2012:133, Fig. 18 \\
\hline Cova d'en Pardo & Inhumación en cueva & $|\mathrm{vd} d| \mid-44 b(7)$ & Beta-202432 & $3080 \pm 40$ & $1406-1294$ & 1431-1231 & Clavicula humana & Soler Díaz 2012: 253, Tabla 10.2a \\
\hline Cueva del Murciélago & Hábitat en cueva & IV (135-136), C-1 & UGRA-342 & $3030 \pm 110$ & $1412-1127$ & $1509-942$ & Carbón & Palomar 1990-91; Gusi y Olària 1995. 145 \\
\hline Pic dels Corbs & Hábitat en cerro & F III. UE 1113. Nivel 5. CE04 & Beta-99443 & $3010 \pm 70$ & $1385-1128$ & 1423-1047 & cereal & Barrachina 2009: 52, tabla 1; 2012: 133, tabla 5 \\
\hline Costamar & Hábitat en litoral & Grupo Est 097. UE 09703 & Beta-264155 & $3000 \pm 40$ & $1367-1131$ & 1391-1114 & Bos taurus & Flors 2010. 163, Fig. 31 \\
\hline El Negret & Hábitat en cerro & UE 1019. Relleno infrapuesto UH 1 & Beta-268986 & $2970 \pm 50$ & $1268-1113$ & 1381-1022 & Diafisis mesomamifero & Barciela et al. 2012: 127, fig. 24 \\
\hline Más d'Abad & Hábitat en cueva & 1 & $1-8935$ & $2960 \pm 85$ & $1288-1042$ & $1408-940$ & Carbón & Gusi 1975; Gusi y Olària 1995: 143 \\
\hline Abric de les Cinc & Hábitat en abrigo & IV A, C-2 & |-10466 & $2920 \pm 90$ & $1259-1000$ & $1392-903$ & Carbón & Gusi y Olària 1995: 143 \\
\hline Cova d'en Pardo & Inhumación en cueva & Nivel II & Beta-124123 & $2920 \pm 70$ & $1215-1015$ & 1373.920 & Fémur humano & Soler Díaz et al., 1999: 121, Tabla 1.2; 2012: 253, Tabla 10.2a \\
\hline Costamar & Hábitat en litoral & Grupo Est 108. UE 10832 & Beta-264154 & $2880 \pm 40$ & 1121-1001 & $1207-931$ & cervus elaphus & Flors 2010: 262, Fig. 32 \\
\hline Pic dels Corbs & Hábitat en cerro & FIII. UE 1114, nivel 5. CE04. & Beta-99441 & $2870 \pm 80$ & $1188-929$ & $1263-843$ & Cereal & Barrachina 2009: 52, tabla 1; 2012: 133, tabla 5 \\
\hline Torrellóde Boverot & Hábitat en cerro & Ue 548 & UBAR-502 & $2860 \pm 50$ & $1111-942$ & $1207-906$ & Carbón & Clausell 2004:173-174 \\
\hline Caramoro ll & Hábitat en terraza & UE21 & CNA-1149 & $2845 \pm 40$ & $1053-931$ & $1124-904$ & Bos taurus & Garcia Borja y Pérez 2012: 41, Fig. 8 \\
\hline Penya Negra & Hábitat en sierra & Pavimento casa "Bull" & GAK-9774 & $2810 \pm 140$ & $1187-820$ & $1413-673$ & Carbón & González Prats 1983.292 \\
\hline Solana del Castell & Hábitat en sierra & UE 11008-1 & Beta-354228 & $2740 \pm 30$ & $906-841$ & $971-816$ & ovicaprino & Pérez Ballester 2014: 24 \\
\hline Torrelló de Boverot & Hábitat en cerro & Ue 71 & $1-16723$ & $2720 \pm 90$ & $976-802$ & $1188-597$ & Carbón & Gusi y Olària 1995: 149; Clausell 2004: 173-174 \\
\hline Botx & Hábitat en Ilano & UE7 & CNA-798 & $2695 \pm 30$ & $893-810$ & $901-806$ & Tniticum-aestivum-durum & Garcia Borja y Pérez 2012: 41, Fig. 8 \\
\hline Penya Negra & Hábitat en sierra & Ilc, fondo cabaña & CSIC-360 & $2690 \pm 50$ & $895-807$ & $970-793$ & Carbón & González Prats 1983: 290 \\
\hline Penya Negra & Hábitat en sierra & $\| c 2$, corte C, Sec $\|$ & CSIC-484 & $2670 \pm 50$ & $894-799$ & $925-784$ & Carbón & González Prats 1983.292 \\
\hline Cova de la Sarsa & Hábitat en cueva & Excavación Ponsell & Beta-322892 & $2650 \pm 40$ & $838-795$ & $899-788$ & Hordeum vulgare & Garcia Borja et al., 2012: 21, tabla 1 \\
\hline Solana del Castell & Hábitat en sierra & Ue 11023-1 & Beta-354230 & $2640 \pm 30$ & $823-797$ & $893-786$ & ovicaprino & Pérez Ballester 2014: 24 \\
\hline La Vital & Hábitat en llano & E10-UE1024 & Beta-331472 & $2620 \pm 30$ & $814-792$ & $831-775$ & Cebada & Garcia Borja et al, 2013: 83 \\
\hline ElMolón & Hábitat en cerro & C3/UE-349 & Beta-136168 & $2620 \pm 70$ & $898-597$ & $927-540$ & Carbón & Lorrio, Inédita \\
\hline Torrelló de Boverot & Hábitat en cerro & Creación recinto 8 & UBAR-458 & $2590+50$ & $824-593$ & $890-542$ & Carbón & Clausell 2004:173-174 \\
\hline Penya Negra & Hábitat en sierra & $\|$ sup., corte B, Sec. \| & CSIC-410 & $2580 \pm 50$ & $813-591$ & $836-541$ & Carbón & González Prats 1983:290 \\
\hline Penya Negra & Hábitat en sierra & Inf. Megaró & CSIC-392 & $2570 \pm 50$ & $808-590$ & $827-540$ & Carbón & González Prats 1983: 290 \\
\hline Cabezo Pequeño del Estaño & Hábitat en cerro & B13 Muestra 2 & CNA-2734.1.1 & $2562+38$ & $804-592$ & $809-547$ & Semillas & Prados, en prensa \\
\hline Fonteta & Hábitat en llano & Fase IUE 3516 & Beta-298122 & $2560 \pm 30$ & $801-599$ & $805-553$ & Stipa tenacissima & García Borja y Pérez 2012:41, Fig. 8 \\
\hline Cabezo Pequeño del Estaño & Hábitat en cerro & B13. Muestra 1 & CNA-2733.1.1 & $2492+38$ & $767-544$ & $790-434$ & Carbón & Prados, en prensa \\
\hline El Molón & Hábitat en cerro & C3/UE-348 & Beta-136169 & $2480 \pm 110$ & $772-489$ & $832-376$ & Carbón & Lorrio, Inédita \\
\hline Penya Negra & Hábitat en sierra & $\| B$, Corte A, Sec. $\|$ & CSIC-413 & $2440 \pm 50$ & $744-411$ & $757-406$ & Carbón & González Prats 1983: 291 \\
\hline Torrelló de Boverot & Hábitat en cerro & Ue-74 & $1-16724$ & $2450 \pm 90$ & $750-415$ & $792-398$ & Carbón & Gusi y Olària 1995: 149; Clausell 2004: 173-174 \\
\hline Torrelló de Boverot & Hábitat en cerro & Ue-63 & $1-16722$ & $2320 \pm 210$ & $755-192$ & $899-77$ & Carbón & Gusi u Olària 1995: 149; Clausell 2004:173-174 \\
\hline
\end{tabular}

Tabla 1. Relación de las dataciones absolutas disponibles para el área en estudio entre el 1450 y el $725 \mathrm{cal}$ BC. Calibradas con el programa OxCal v.4.2.3., según la curva atmosférica IntCal13 (Reimer et al. 2013). 


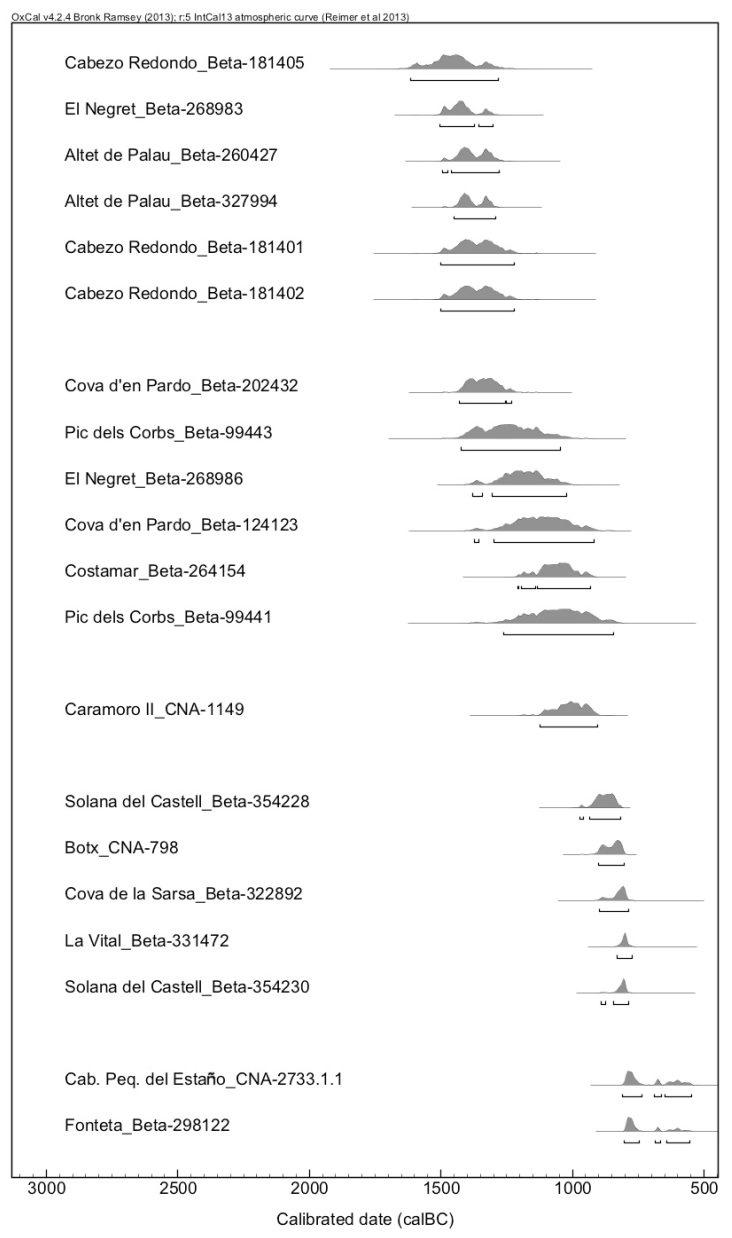

Figura 2. Gráfico con las curvas de calibración de las dataciones absolutas sobre muestra de vida corta disponibles del ámbito geográfico en estudio. Programa OxCal v.4.2.3., según la curva atmosférica IntCal13 (Reimer et al. 2013).

incluido las dataciones sobre muestras de vida corta, podemos observar la existencia de diversas concentraciones de dataciones y ciertos vacíos sin dataciones, asociados al abandono de algunos de los asentamientos a los que aquí nos hemos referido. Es el caso del abandono de Altet de Palau y Cabezo Redondo hacia c. 1300/1250 cal BC; de Pic dels Corbs en su fase III-IV y algunas de las estructuras negativas documentadas en Costamar hacia el tránsito del II al I milenio cal BC; de la Vital y Solana del Castell en su primera fase hacia mediados del siglo IX cal BC; y también, las dataciones más antiguas disponibles para los niveles fundacionales de asentamientos coloniales costeros como Cabezo Pequeño del Estaño ${ }^{6}$ y la primera de las fases de ocupación de la Fonteta, que situaría su comienzo hacia mediados del siglo VIII cal BC.

Por tanto, la periodización que a continuación presentamos parte de la valoración de una serie de procesos o hitos de fundación, transformación arquitectónica y uso, pero especialmente de abandono, documentados en los asentamientos publicados, avalados, por el momento, por algunas dataciones absolutas. Estos hitos que implican abandonos o cambios en la organización de las áreas de residencia, y por extensión de la ocupación del territorio, suelen coincidir temporalmente en más de un asentamiento. En este sentido, son muy pocos los yacimientos que cuentan con varias dataciones absolutas que permitan determinar en el tiempo dichos procesos. En concreto, solamente Cabezo Redondo, Pic dels Corbs, Altet de Palau, El Negret, la Solana del Castell, Costamar, Cova d'en Pardo, Caramoro II, Barranc del Botx y La Vital, permiten ubicar temporalmente alguno de sus momentos de ocupación a partir de algunas dataciones efectuadas sobre muestras de vida corta. Algunas de las dataciones son coincidentes cronológicamente, estando asociadas a momentos de uso y/o abandono. Este armazón se complementa con otros yacimientos cuyos niveles de ocupación cuentan con alguna datación sobre muestras de vida larga y desviaciones estándar muy amplias, pero con un repertorio material que se puede asociar por tipología cerámica a cada uno de los momentos demarcados.

La falta de mayor concreción cronológica para algunos de los yacimientos más representativos del área en estudio se debe, esencialmente, a la falta de dataciones absolutas asociadas a contextos arqueológicos con repertorios materiales. Esta cuestión ha sido matizada a partir del estudio y comparación de algunos de los repertorios cerámicos excelentemente seriados (García Borja y Pérez 2012; Pérez Ballester 2014).

Una situación parecida a la aquí planteada, se observa, tanto en las tierras del Noreste como del Sureste peninsular. El número de dataciones absolutas disponibles se muestra insuficiente (Castro, Lull y Micó 1996; López Cachero 2008; Ruiz Zapatero 2014; Lorrio 2008), procediendo en su mayor parte de muestras de vida larga y con una limitada información sobre el contexto de procedencia. En el caso del Noreste peninsular, se han realizado un amplio número de propuestas de periodización (López Cachero 2008), no exentas de problemas, tanto en relación con el número y calidad de las dataciones absolutas, como en relación con la imposibilidad de demarcar "objetos-tipo" 


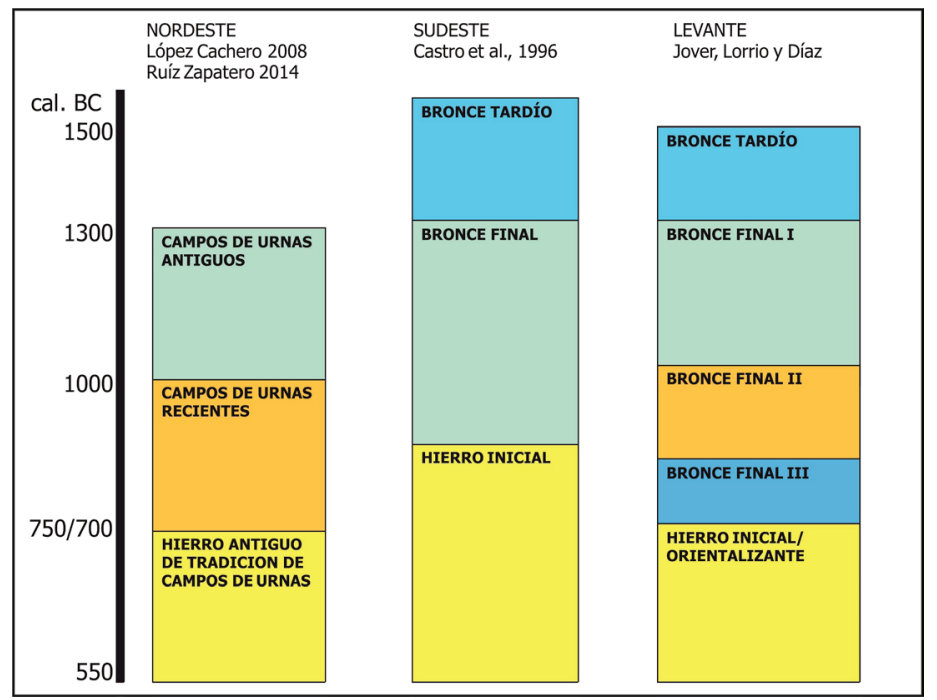

Figura 3. Cuadro comparativo de las diferentes propuestas de periodización vigentes para los ámbitos territoriales del Noreste y Sureste peninsular, incorporando la efectuada en el presente texto.

para cada una de las fases o periodos diferenciados (López Cachero 2008; Ruiz Zapatero 2014). No obstante, lo que sí parece evidente, a partir de los contextos datados y de algunos cambios en las prácticas sociales y en la cultura material es que, a grandes rasgos, se puede diferenciar entre un Bronce final antiguo/Bronce final II o Campos de Urnas antiguos, desarrollado entre el 1300 y el 1000 cal BC, momento en el que hace su aparición las cerámicas acanaladas; una segunda fase, denominada como Bronce final reciente/Bronce final III o Campos de Urnas recientes, entre el $1000 / 900$ y $750 / 700 \mathrm{cal} \mathrm{BC}$, en la que comienza a constatarse las prácticas funerarias de incineración, además de un desarrollo heterogéneo de las cerámicas acanaladas; y una Edad del Hierro antiguo o Grupo del Hierro I de tradición de Campos de Urnas (Ruiz Zapatero 2014: 211), a partir de finales del siglo VIII cal BC.

Por su parte, en el Sureste, la propuesta de F. Molina (1978) elaborada a partir de las secuencias estratigráficas de diversos yacimientos sigue siendo útil, con las debidas matizaciones cronológicas introducidas con la calibración dendrocronológica, aunque con posterioridad se hayan efectuado otras propuestas de periodización utilizando, o bien mediciones radiométricas (Castro, Lull y Micó 1996), o bien, secuencias y seriaciones funerarias (Lorrio 2008; Pernas 2012). Atendiendo a la propuesta de Castro, Lull y Micó (1996: 195) se podría distinguir un Bronce tardío entre el 1550 y el 1300 cal BC -fase que sería coetánea con la primera de las planteadas para el Grupo Segre-Cinca del área del Nordeste (Castro, Lull y Micó 1996: 179)-; un Bronce final pleno, demarcado cronológicamente entre el 1300 y 900 cal BC, y un Bronce final reciente (III) o Hierro inicial a partir de inicios del siglo IX cal BC. El escaso número de dataciones para el periodo del Bronce final pleno no permitiría delimitar fases dentro de ese gran periodo global.

Por otro parte, Lorrio (2008), a partir de la revisión de los contextos funerarios del Bronce final del Sureste, proponía una periodización en tres fases, que abarca entre los siglos X-IX y el 700 a.C., aunque las manifestaciones más tardías se extiendan a lo largo de la primera mitad del siglo VII a.C., por tanto ya dentro de la Edad del Hierro (Lorrio 2008: 324 ss., tab. 48). Lo que en gran medida coincide con la revisión de la cronología radiocarbónica disponible para el Sureste (Torres 2008: 541). La gran mayoría de las tumbas se engloban en las fases II y III, que se asimilan con las fases plena y reciente del Bronce Final según la clasificación de Molina (1978). La Fase II se equipara en gran medida con el Bronce final pleno, fechado a partir del siglo IX, mientras que la más reciente, o Fase III, remite tanto al Bronce Final III (IIIA) como a contextos ya plenamente orientalizantes (IIIB), un periodo de transición que se extiende desde mediados del siglo VIII a.C., o quizás algo antes, hasta bien entrado el VII, en el que las sociedades del Sureste se encaminarían paulati- 
namente hacia un nuevo escenario que supondrá la radical transformación del panorama funerario. No obstante, la presencia en algunos pocos casos de materiales de mayor antigüedad haya conducido a proponer una fase previa, que parece corresponder con el clásico Bronce final I del Sureste.

En cualquier caso, y a pesar de las dificultades expuestas, la periodización que aquí presentamos (Fig 3), también ha tenido como apoyo las propuestas realizadas en estos territorios próximos, situados tanto al norte (López Cachero 2008; 2011; Pons 2012; Ruiz Zapatero 2014), como al sur (Castro, Lull y Micó 1996; Lorrio 2008; Lull et al., 2011) del Levante peninsular. No obstante, en nuestro caso, sí se ha intentado delimitar lo más posible las fases, a tenor de los cambios observados en el registro arqueológico, y siendo conscientes de que las horquillas cronológicas establecidas para cada fase, deben ser tomadas como una referencia sujeta a cambio y no como una fecha avalada estadísticamente.

Por último, indicar que la denominación otorgada a las diversas fases establecidas sigue la nomenclatura que tradicionalmente se han venido aplicando por parte de numerosos investigadores, aunque sea difícil acompasarla con el amplio número de propuestas efectuadas. No obstante, también acompañamos dicha denominación con el periodo temporal que abarcaría y el aspecto que, según los datos disponibles, lo caracterizaría. Las fases propuestas para las tierras del Levante peninsular se concretan en:

\subsection{Bronce tardío o reciente (c. 1550/1500- $1300 / 1250$ cal BC)}

Como se ha señalado en otros trabajos (Jover y López 2009; Hernández, Jover y López 2013), desde el 1750 cal BC ya se advierten diversos cambios en el registro arqueológico de las tierras levantinas, que anuncian algunas de las aspectos que van a caracterizar la fase denominada como Bronce tardío. Estos cambios se pueden relacionar con el aumento del tamaño de algunos asentamientos, algunos ubicados en nudos de comunicación; con la generalización de la aleación de bronce y en la constatación de cambios en el repertorio cerámico (De Pedro 2004; Hernández, Jover y López 2013). A los momentos previos al Bronce tardío corresponden el mayor número de dataciones absolutas efectuadas hasta ahora (Jover, López Padilla y García-Donato 2014).
No obstante, hacia finales del siglo XVI cal $\mathrm{BC}$ comienza a evidenciarse importantes transformaciones en el patrón de asentamiento, que culminará con el abandono de buena parte de los yacimientos ocupados en el ámbito de El Argar (Lull et al., 2009; 2013) y en las tierras valencianas (De Pedro 2004; Jover y López 2004; 2009; Hernández, Jover y López 2013). A partir de 1550-1500 cal BC, en El Argar se constata una nueva fase de ocupación en yacimientos como Gatas -fase V- (Castro et al., 1999) o Fuente Álamo -fase V- (Schubart, Pingel y Arteaga 2000), iniciando el denominado Post-argar (Castro, Lull y Micó 1996) o Bronce tardío (Molina 1978). En las tierras valencianas, asentamientos como Terlinques (Jover y López 2009), Lloma de Betxí (De Pedro 1998; 2004), Puntal dels Llops (De Pedro 2004: 4749) o Pic dels Corbs en su fase II (Barrachina 2012: 133-134), junto a muchos otros, parecen abandonarse, o en algunos casos, transformarse ampliamente, a tenor de las dataciones absolutas disponibles. En otros, como en Cabezo Redondo, las dataciones absolutas muestran que su fundación se pudo llevar a cabo en torno al 1750-1700 cal BC, mientras que hacia el 1500 cal $\mathrm{BC}$, en su secuencia se constata diversos incendios e importantes transformaciones arquitectónicas (Hernández 2009; 2012), que suponen una importante reestructuración, dando inicio a la fase denominada como Bronce tardío. Del mismo modo, se ha planteado la posibilidad de que en estos momentos se produjese un importante proceso de nuclearización poblacional de los pobladores de la cubeta de Villena hacia este asentamiento (Jover y López 2009; Hernández, Jover y López 2013), que también podría hacerse extensible a otros valles. No obstante, es posible que este proceso se iniciara en momentos previos al colapso político propuesto para la entidad social argárica (Lull et al., 2013).

Por tanto, las dataciones absolutas disponibles, suficientemente amplias en Cabezo Redondo (Hernández 2009; 2012), empiezan a configurar una fase arqueológica entre finales del siglo XVI e inicios del siglo XIII cal BC. Junto a la última de las grandes fases arquitectónicas detectadas en Cabezo Redondo, también cabe situar la unidad habitacional 2 de El Negret (Barciela et al., 2012), El Altet de Palau (García Borja y De Pedro 2013), con dos dataciones sobre muestras de vida corta para su posible abandono; la ocupación final de Les Raboses (Ripollés 2000), y con probabilidad, sendas ocupaciones en El Torrelló 
d'Onda y Orpesa la Vella (Barrachina y Gusi 2004). No obstante, no se puede descartar que estos últimos, datadas sobre muestras de vida larga, puedan corresponder ya a niveles de la siguiente fase, más aun si tenemos en cuenta los conjuntos materiales publicados (Gusi y Olària 2014).

Así, durante el Bronce tardío se produciría la fundación de nuevos enclaves como L'ArbocerAltet de Palau (García Borja y De Pedro 2013), y la continuidad en la ocupación de otros situados en puntos estratégicos en los principales corredores de comunicaciones -El Negret (Barciela et al., 2012)-. Desconocemos si determinados embarcaderos costeros como la Illeta del Banyets (Simón 1997; Soler Díaz 2006; 2009), con una destacada ocupación durante El Argar, siguen manteniendo su vigencia, o se reactivan en la fase posterior, durante el Bronce final I, en clara relación con otros enclaves situados en diversos promontorios con condiciones naturales apropiadas para el atraque, caso de zonas más septentrionales como Cap Prim y Orpesa (Simón 1987; 1997).

Por tanto, es difícil, por el momento, atendiendo exclusivamente a la cerámica documentada, determinar si, yacimientos como Cap Prim (Simón 1987), Peña de Sax (Hernández y Pérez 2005) o la Illeta dels Banyets (Simón 1997; Soler Díaz 2006), considerado este último ya desde hace años como uno de los yacimientos claves para el estudio de este periodo, estuvieron ocupados durante esta fase, durante la siguiente, ya en el Bronce final I, o bien en ambas. La similitud de los repertorios materiales hace que sea difícil concretar la adscripción cronológica para las evidencias detectadas hace años en estos enclaves (Fig 4).

Con todo, por el momento, Cabezo Redondo (Soler García 1987; Hernández 1997; 2001) sigue siendo el principal yacimiento para caracterizar dicha fase, no sólo por la serie de dataciones absolutas disponibles (Hernández 2009; 2012), sino también por sus características estructurales $\mathrm{y}$ calidad de la información obtenida. Se trata de un asentamiento cuyo tamaño se aproximaría a las dos hectáreas, sin evidencias de murallas pero con un hábitat claramente planificado con aterrazamientos en ladera, con calles y una compleja planificación urbanística del espacio con agrupaciones de casas y áreas de actividad entre unidades departamentales y al interior de cada una de ellas (Hernández 2001; 2009; Hernández et al., 2012)

Por otro lado, el conjunto material es muy variado. En relación con la vajilla cerámica, cabe indicar la presencia de un repertorio muy amplio de formas, simples y carenadas, con diversos tra-

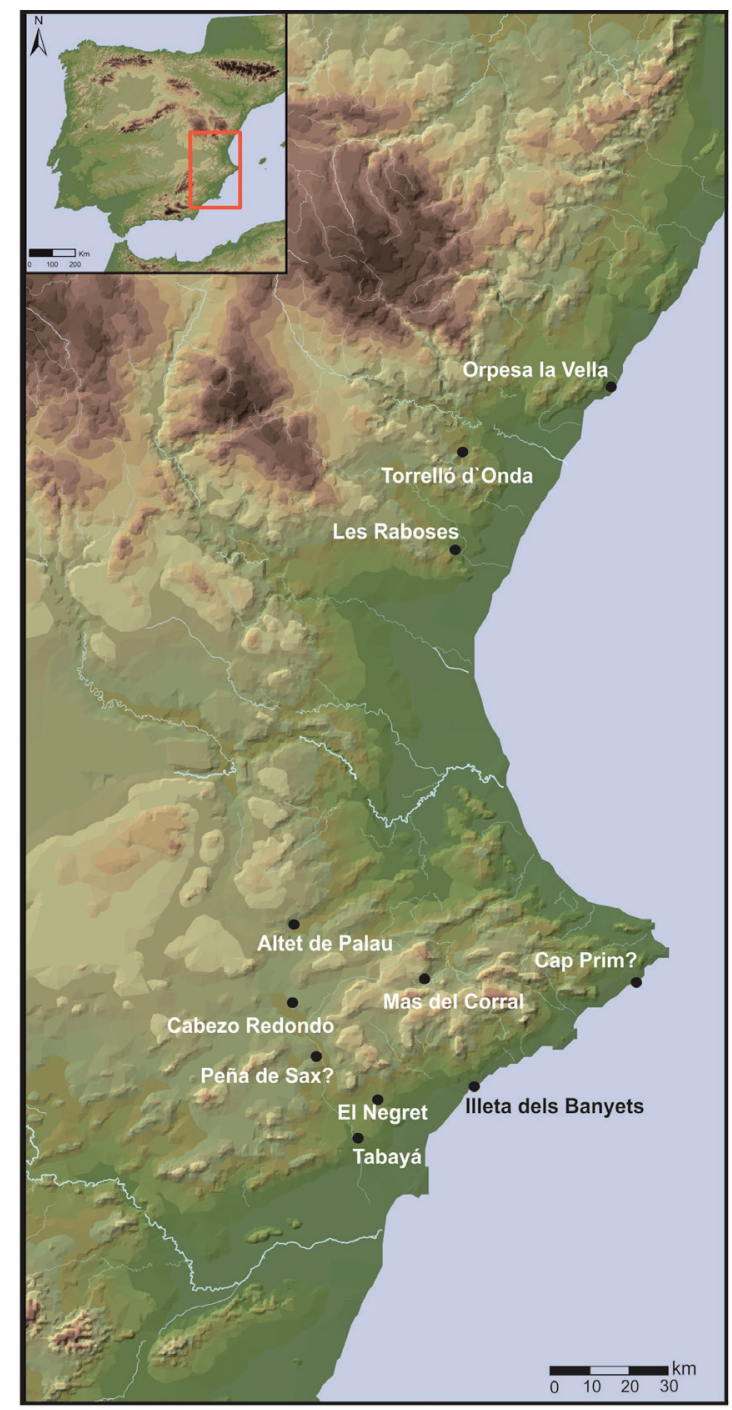

Figura 4. Mapa del este peninsular con indicación de los principales yacimientos arqueológicos del Bronce tardío citados en el texto.

tamientos y acabados. Entre las formas carenadas destaca la presencia de cuencos y cazuelas de carena alta y borde diferenciado, y formas cerradas con carenas muy agudas. Acompañando los vasos simples, destaca un muy bajo porcentaje de vasos decorados, inferior al $0,3 \%$ del total, con diversas técnicas -incisión, impresión, boquique y excisión- y motivos -zigzags, espigas, guirnaldas, etc.-- La metalurgia también destaca por la gran importancia de la orfebrería, especialmente del oro, así como la existencia de tipos específicos de otros elementos de la cultura material, como son los instrumentos y adornos de materias 
óseas (López Padilla 2011) y también de pesas de telar cilíndricas con perforación central (Hernández 1994).

No obstante, la complejidad registrada en Cabezo Redondo no es extensible, por ahora, a otros poblados, de los que, por otra parte, tampoco se conoce ninguno que lo iguale en tamaño, ya que en fechas sincrónicas en la zona de estudio, solamente se constatan asentamientos con extensiones superficiales inferiores a $3.500 \mathrm{~m}^{2}-\mathrm{El}$ Negret (Barciela et al., 2012), aunque no toda su extensión parece corresponder a esta fase- $\mathrm{y}$ otros de todavía mucho menor tamaño, en torno o por debajo de los $1.000 \mathrm{~m}^{2}$, como es el caso de L'Arbocer-Altet de Palau (García Borja y De Pedro 2013). En este asentamiento, excavado prácticamente en su mitad, se ha detectado un importante muro de cierre del espacio de hábitat, con una posible torre - o contrafuerte- así como una calle o pasillo de un metro de anchura, en torno al que se localizan diversas estancias de dimensiones variadas. En ellas se ha documentado un repertorio material bastante escaso y fragmentado como consecuencia de los importantes procesos erosivos que afectaron al depósito. Entre otros, destaca la documentación de un vaso de carena gruesa y marcada en el tercio superior, una base plana ligeramente talonada, un variado repertorio de objetos de cobre o bronce y una lámina perforada de plata decorada con líneas acanaladas (García Borja y De Pedro 2013: 77-78).

Todo parece indicar, que estos cambios en la organización social y territorial, que, desde un punto de vista arqueológico, darían comienzo a la fase del Bronce tardío, son mucho más perceptibles por el momento en las comarcas meridionales valencianas, que en las más septentrionales (De Pedro 2004). No obstante, algunos autores (De Pedro 2004; Barrachina y Gusi 2004) también han señalado cambios en las tierras septentrionales en lo que respecta al patrón de asentamiento y algunos elementos de los ajuares domésticos. Sin embargo, mientras las zonas del Prebético meridional valenciano están claramente relacionadas con la dinámica histórica y política del Sureste (Jover y López 2009), sin que podamos determinar, por el momento, si estamos ante una descomposición política o ampliación de El Argar, en las tierras septentrionales se desarrollarían otras entidades sociales, donde la relaciones económicas y políticas con el Sureste son menos evidentes.

Todos estos cambios, también se reflejan en la tipología e incremento de la eficacia de algunos instrumentos de trabajo, en una vajilla cerámica a la que se van a incorporar nuevas formas carenadas, especialmente más agudas, gruesas y situadas en el tercio superior de los vasos, mejores tratamientos y nuevas técnicas decorativas como la incisión o el boquique de claro origen meseteño (Abarquero 2005), a lo que debemos sumar diversos productos de clara procedencia alóctona como son los pomos, los peines de marfil, las puntas de lanza de base hueca de bronce, las cuentas de pasta vítrea o de ámbar (Hernández 2001 ; 2005) y un importante conjunto de adornos de oro, tanto en tumbas como en ocultaciones -tesorillo de Cabezo Redondo (Soler García 1987)-. Este conjunto de cambios va asociado al desarrollo de prácticas de inhumación individual en el interior de algunos poblados, como es el caso de Mas del Corral (Trelis 1992), o en grietas y cavidades, ya que las inhumaciones practicadas en el interior de los departamentos de Cabezo Redondo que han sido datadas no se documentan más allá del 1500 cal BC (Hernández 2009).

\subsection{Bronce final I (c. 1300/1250-1000 cal BC)}

Los cambios y transformaciones que se empiezan a determinar en distintos yacimientos del Levante peninsular y que también se pueden relacionar con cambios producidos en las tierras del Sureste (Castro et al., 1999), permiten proponer una nueva fase arqueológica cuyos inicios habría que fijar hacia el 1300/1250 cal BC. En estos momentos se constata el abandono definitivo de asentamientos tan destacados como Cabezo Redondo (Hernández 2009; 2012; Jover, López y García Donato 2014), l'Altet de Palau (García Borja y De Pedro 2013) o Más del Corral (Trelis 1992). En otros, también se determinan transformaciones arquitectónicas de importancia, como en El Negret (Barciela et al., 2012).

Hace unos años, el denominado Bronce final, cuyos inicios debemos fijar a partir de los cambios señalados, constituía un "saco sin fondo" en el que se incluía una gran cantidad de yacimientos (Mata, Martí e Iborra 1994/96). La propuesta de fasificación de Gil-Mascarell y Aranegui (1981), a partir de la secuencia desarrollada por Molina (1978) para el Sureste, ha constituido el armazón que ha venido sustentado todo intento de clasificación, aun cuando la separación entre el Bronce tardío o reciente y Bronce final I todavía no está resuelto en las secuencias de ocupación de muchos de los yacimientos excavados hace décadas. Es el caso de yacimientos como Orpesa la Vella en su fase III (Barrachina y Gusi 2004; Gusi 
y Olària 2014) o La Illeta del Banyets (Simón 1997; Soler Díaz 2006). Tampoco ha contribuido a ello el hecho de que el número de yacimientos conocidos sea escaso y mucho menos excavados en extensión.

No obstante, en los últimos años se han dado importantes pasos hacia la corrección de este problema. La secuencia del asentamiento del Pic dels Corbs en sus diversas fases (Barrachina 2009; 2012), unido a otros como Costamar (Flors 2010), El Negret (Barciela et al., 2012) o El Botx-Grupintex (Trelis et al., 2004; García Borja y Pérez 2012: 42-43), constituyen las referencias obligadas para el desarrollo de una fasificación arqueológica (Fig 5), aun a riesgo de tener que ser mejorado cuando contemos con nuevas bases estratigráficas y series radiocarbónicas.

Así, hace unos años, ya se planteaba (Jover 1999) que a partir del Bronce final -o fase IV de aquel trabajo- se produciría un importante abandono de muchos de los yacimientos ubicados en cerros, a la vez que parecía intensificarse la ocupación de enclaves en llano. Algunos asentamientos en cerros o estribaciones montañosas, como Tabayá, al parecer, siguieron siendo ocupados (Hernández y López 1992; Molina Mas 1999; Belmonte 2004), mientras que para otros, como Mola d'Agres, se proponía un traslado del área ocupada a otras zonas del mismo cerro - sector V y VII- (Gil-Mascarell y Peña 1994; Peña et al., 1996), aún cuando actualmente parece existir un hiato ocupacional durante las fases del Bronce tardío y final I aquí propuestas.

También parece ser significativa, para estos momentos, la constatación de ocupaciones puntuales, quizá de carácter estacional, y de alguna inhumación en cuevas como la Cova de la Pastora (McClure et al., 2011) o la Cova d'en Pardo (Soler Díaz et al., 1999; Acosta y López Padilla 2012), además de una más que clara ocupación de los fondos de valle y zonas litorales, como es el caso de Costamar (Flors 2010). En cualquier caso, un indicador material que se podía considerar como diagnóstico ante la falta de dataciones absolutas es la presencia de cerámicas decoradas del tipo Cogotas I (Rodríguez y Fernández 2012) y fuentes, platos o escudillas carenadas con inflexiones acusadas (Jover 1999).

Con todo, las mejores bases estratigráficas, debidamente datadas, para esta fase en la zona de estudio, las constituyen los yacimientos septentrionales de Pic dels Corbs (Barrachina 2009; 2012) y Costamar (Flors 2010). Para el primero de ellos, se han dado a conocer una amplia infor-

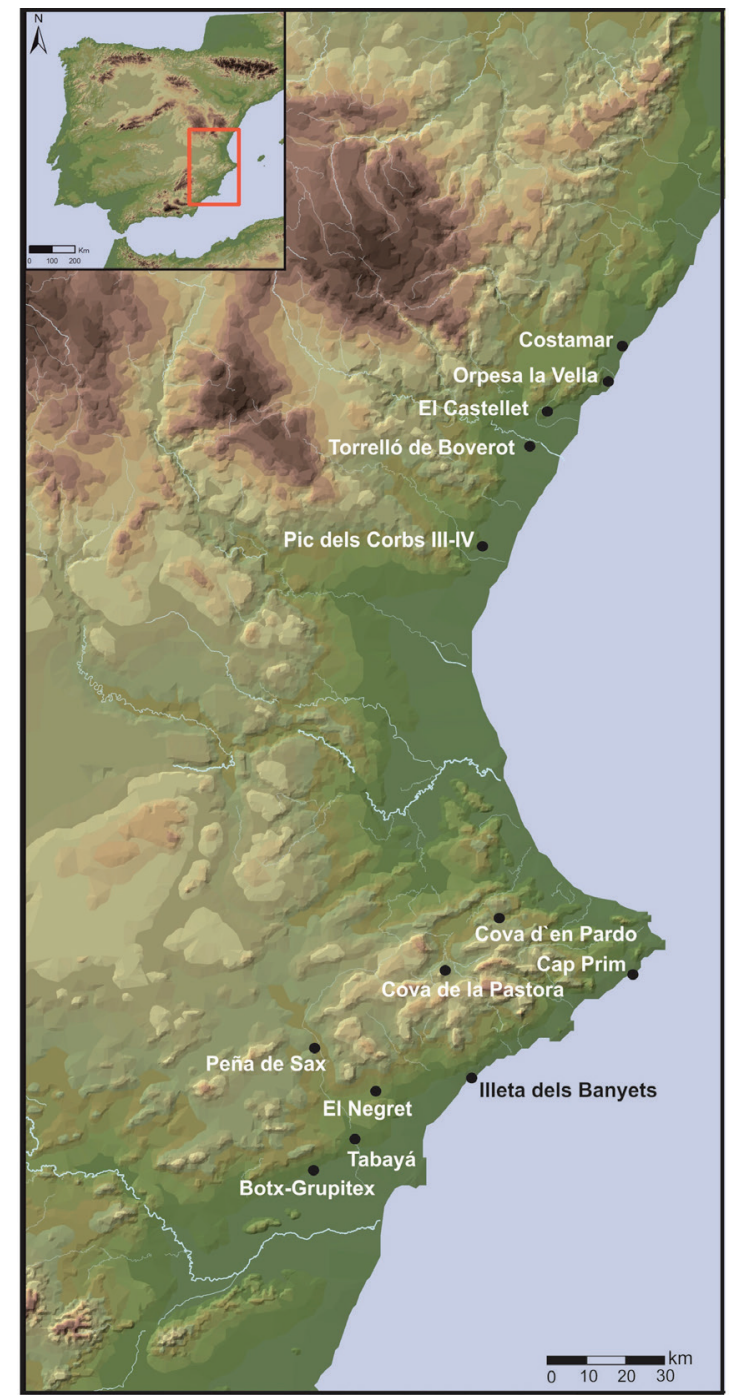

Figura 5. Mapa del este peninsular con indicación de los principales yacimientos arqueológicos del Bronce final I citados en el texto.

mación de las fases III y IV (Barrachina 2012: $63-79 ; 133-134$, tabla 5), cuyas dataciones absolutas se sitúan en este intervalo cronológico y la cultura material constatada supone una auténtica transformación con respecto a la fase II. Una datación sobre una muestra de vida corta, en concreto bellotas -Beta-99441: 2870 \pm 80 BP/1263-843 cal BC $(2 \sigma)$ - indicaría, con mayor fiabilidad, el momento de abandono de esta fase que afectaría, al menos, a un conjunto de tres unidades habitacionales y a un área de basurero (Barrachina 2009: 53-54; 2012: 63-79). Entre el repertorio cerámico de Pic dels Corbs, es destacable la presencia de un variado conjunto de bases planas, algunas con 
talón marcado, incluso con decoración digitada. Entre las técnicas decorativas destaca la incisión, impresión de círculos, el boquique combinado en ocasiones con punteado y la excisión. También es importante la ausencia de urnas acanaladas en las fases de ocupación III y IV, cuya presencia en el Noreste peninsular ya está atestiguada (López Cachero 2007; 2008) en momentos avanzados de esta fase, al parecer, con anterioridad a la existencia de necrópolis de incineración (López Cachero 2007: 102, fig.1; 2011; Pons 2012). No obstante, el hecho de que las dataciones absolutas disponibles en contextos de hábitat del área catalana sean todas sobre muestras de vida larga -carbón-(López Cachero, 2007: 103, tab.1), obliga a rejuvenecer su presencia a momentos avanzados de esta fase. Por último, en cuanto a repertorio material, también es reseñable la producción en hueso de mangos y peines decorados con motivos triangulares incisos (Barrachina 2009: 52).

Con respecto al yacimiento costero de Costamar (Flors 2010), las excavaciones han permitido interpretar la existencia de fondos de cabaña realizados con materiales endebles y áreas de desecho con un amplio repertorio cerámico decorado similar a las fases III y IV del Pic dels Corbs e, igualmente, sin urnas acanaladas. Una de las dataciones sobre una muestra de vida corta coincide plenamente con el final de la fase III de Pic dels Corbs.

En esta fase también se deben incluir los registros de otros yacimientos, algunos de ellos con alguna datación, lo que viene a reforzar su individualización. Es el caso de la procedente del preparado sobre el que se edifica la unidad habitacional $\mathrm{n}^{\circ} 1$ de El Negret (Barciela et al., 2012), del que no se puede indicar mucho más ante la exigüidad del material asociado recuperado; de la ocupación y evidencias funerarias de la Cova d'En Pardo (Soler Díaz et al., 1999; Acosta y López 2012: 283, Fig. 13.3), en el que destaca la presencia de algunas bases planas talonadas y fragmentos cerámicos decorados con motivos incisos, algunos de los cuales podrían llevarse también a la siguiente fase. En otros yacimientos excavados, como El Castellet (Oliver, García y Moraño 2005), se ha individualizado en su sector 1 , niveles que deben corresponder a esta fase, al documentarse cerámicas decoradas similares a Pic dels Corbs, y la ausencia de las cerámicas acanaladas. Lo mismo ocurre en la fase III de Orpesa la Vella (Barrachina y Gusi 2004; Gusi y Olària 2014) o, también, en el Torrelló de Boverot (Clausell 2004), cuya larga ocupación y a fal- ta de una publicación detallada de su secuencias estratigráficas, sólo cabe deducir su presencia. Otras evidencias que parecen situarse en estos momentos, corresponden a algunas de las estructuras negativas excavadas en el El Botx-Grupitex (Trelis et al., 2004), con una importante lote de materiales amortizados para los que no se dispone de dataciones.

En cualquier caso, el problema sigue residiendo en la imposibilidad, por el momento, de diferenciar, desde la perspectiva del repertorio cerámico, el Bronce tardío del Bronce final I, como ya se ha manifestado anteriormente en relación con asentamientos excavados como la Illeta dels Banyets (Soler Díaz 2006), para los que no se cuenta con dataciones absolutas que permitan encuadrar cronológicamente dicha ocupación.

\subsection{Bronce final II (1000-850 cal $\mathrm{BC})$}

El abandono, reestructuración arquitectónica o fundación de nuevos asentamientos que se detecta hacia el tránsito del II al I milenio cal BC, especialmente, en lo que atañe a buena parte de las comarcas septentrionales y centrales del área valenciana, también parece coincidir con diversos cambios en el Noreste peninsular (Ruiz Zapatero 2001a; 2001b; 2014; López Cachero 2008: 61; 2011) donde, además de un poblamiento estable y organizado, se advierten la generalización de las necrópolis de cremación, cuya definitiva consolidación y extensión en todo el territorio parece producirse una vez entrado el I milenio cal BC (Pons 2012).

Para las tierras valencianas es probable, por tanto, que entre la ocupación de Costamar y las fases III-IV de Pic dels Corbs, cuyo final podríamos situar hacia finales del II milenio cal BC, y la fundación de Penya Negra (González Prats 1983; 1990), cuyo inicio según las dataciones radiocarbónicas disponibles remitiría a pleno siglo IX cal $\mathrm{BC}$, se individualice una nueva fase arqueológica, de difícil definición por el momento, ante la diferente incidencia de los tradicionalmente denominados como "Campos de Urnas" sobre el territorio (Ruiz Zapatero 2001a; 2014). Esta fase estaría presente y representada a nivel el material en yacimientos como Pic dels Corbs en su fase V (Barrachina 2012: 87-107), coincidiendo con una amplia reestructuración arquitectónica, en la que se detecta, además, una ocupación más intensa en la zona sur del cerro, una tendencia a viviendas con muros más curvos, o al menos, absidales, y la presencia entre el registro domés- 
tico de urnas acanaladas, además de otros objetos hasta ahora inéditos en estas tierras (Barrachina 2012: 87-107); en el importante asentamiento de la Solana del Castell (Pérez Ballester 2014: 24), en cuya fase inicial o I se ha detectado un tramo de muro y calzos de poste asociados a un importante lote de materiales cerámicos; también en el asentamiento amurallado de Caramoro II (González Prats y Ruiz 1992; García Borja et al., 2010) con una datación absoluta de finales del II milenio cal BC (García Borja y Pérez 2012: 41, fig.8), y en el que se documentó una urna cerámica con restos cremados; en la ocupación de los sectores V y VII de Mola d'Agres (Gil-Mascarell y Peña 1994; Peña et al., 1996) con evidencias de urnas de tipología antigua, aunque no se cuente con ninguna datación; y también, más al sur de las tierras valencianas, en la fase VI de Gatas (Castro et al., 1999), datada por C-14, en la que también destaca la presencia de un fragmento de urna acanalada.

Esta misma fase también parece estar presente -entre otros yacimientos-, ante la documentación de niveles con urnas acanaladas, en Cova de les Bruixes (Mesado 2005), Ereta del Castellar (Ripollés 2000: 177), El Castellet (Oliver, García y Moraño 2005), Torrelló de Boverot (Clausell 2004), Tabayá (Hernández y López 1992), así como en muchos otros yacimientos señalados por Mata, Martí e Iborra (1994/96).

Una cuestión fundamental que se puede inferir del registro arqueológico de esta fase en la zona de estudio (Fig. 6), si lo comparamos con las fases plenas de la Edad del Bronce, es la constatación de un claro descenso del número de asentamientos y la continuidad de procesos de desagregación poblacional iniciados en la fase previa. Todo lo contrario parece ocurrir en las tierras catalanas, donde la estabilidad y el crecimiento poblacional parece ser un hecho contrastable (López Cachero 2007; Pons 2012).

En cualquier caso, lo que sí parece evidente es el inicio de un proceso de basculación o traslado de parte de la población hacia las zonas costeras, en clara relación con la intensificación del intercambio por vía marítima (Jover 2006; Gusi et al., 2010). Un buen número de evidencias se localizan a partir de estos momentos en las franjas litorales, entre los que merece destacar la Depresión litoral alicantina -donde ya durante el II milenio cal BC se constataba una mayor densidad poblacional (López Padilla 2009)-, mientras algunos de los valles interiores, como el curso Alto y Medio del Vinalopó, que habían sido ocupadas

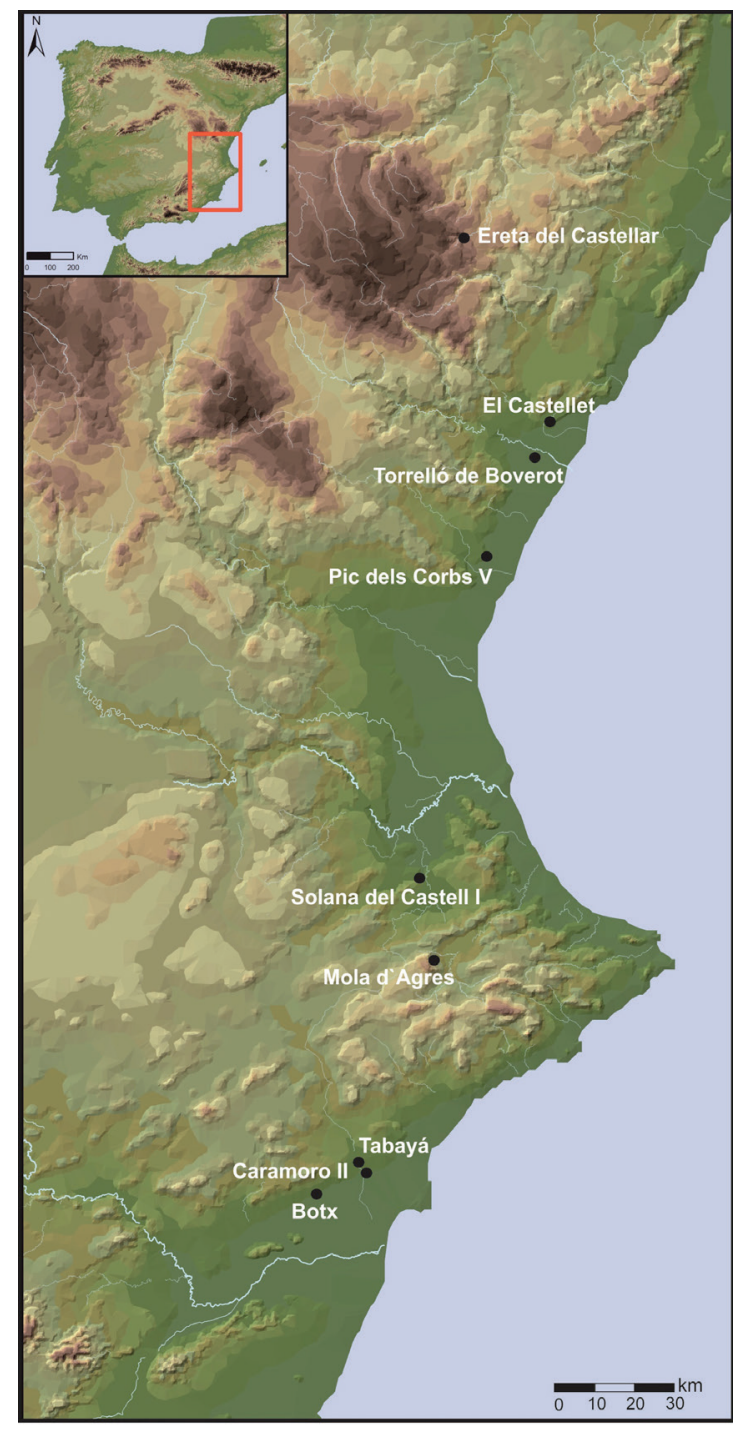

Figura 6. Mapa del este peninsular con indicación de los principales yacimientos arqueológicos del Bronce final II citados en el texto.

de forma importante en las fases previas, parecen abandonarse.

Así, en las sierras que delimitan la depresión litoral alicantina, se localizan dos de los asentamientos más importantes ocupados durante esta fase. Uno de ellos, que parece mantener cierta continuidad poblacional desde momentos campaniformes hasta el Bronce final es Tabayá (Navarro 1982). Aunque no se cuenta con dataciones absolutas, este asentamiento de gran tamaño, presentaría ocupaciones durante el Bronce tardío (Belmonte 2004), Bronce final I (Molina Mas 1999), y, en especial, del Bronce final II de 
esta propuesta, dado el conjunto de materiales cerámicos publicados, en concreto, un destacado repertorio de vasos acanalados (Hernández y López 1992; García Borja y Pérez 2012: 50$53)$, vinculados claramente con los Campos de Urnas. No obstante, mientras no se publique con detalle la información estratigráfica y secuencial del mismo, no se podrá concretar el carácter y la importancia de cada una de las ocupaciones y la existencia o no de hiatos entre ellas. Además, se han atribuido al Tabayá dos "lingotes-hacha" conservados en el Museo de Novelda, semejantes a otras recuperadas en Penya Negra y Fonteta, donde se fechan entre los siglos VIII y VI a.C. (González Prats 1985b; Renzi 2010), aunque se desconozca la procedencia segura de las piezas y las condiciones del hallazgo, lo que es igualmente extensible a un conjunto de cerámicas grises orientalizantes con similar procedencia (C. Navarro, comunicación personal), quizás procedentes de algún yacimiento localizado en la sierra del Tabayá.

Por otro lado, las excavaciones efectuadas en Caramoro II, yacimiento fortificado ubicado en el umbral montañoso que delimita el corredor de la Vega Baja-Camp d'Elx, han puesto en evidencia la ausencia de cerámicas inciso-impresas y pintadas, propias del horizonte Penya Negra I, al tiempo que la presencia de cerámicas acanaladas, así como de un fragmento cerámico con incrustaciones metálicas (González Prats y Ruiz 1992; García Borja et al., 2010: 49), cuyos paralelos han sido fechados a lo largo del siglo X-IX a.C. (Torres 2008). Destaca la documentación de vasos con una doble ruptura en el perfil y en diferentes clases formales, una alta representación de bordes vueltos asociados a fuentes, cuencos y contenedores de tamaño grande y mediano, algunos con decoración acanalada (García Borja y Pérez 2012: 48). Además, las excavaciones de salvamento han permitido constatar el ritual funerario de la cremación por vez primera en la zona (García Borja et al., 2010: 54-55, fig. 13), aunque con unas características, una tumba aislada, y una localización, a intramuros del poblado, claramente anómalas, explicables posiblemente por su alta cronología (Lorrio 2009-2010: 154). Se ha propuesto una cronología para el asentamiento de los siglos XI y X cal BC a partir de una datación radiocarbónica (García Borja y Pérez 2012: 41, Fig. 8) y del repertorio cerámico (García Borja et al., 2010: 62), lo que desvincularía el yacimiento de cualquier relación con Penya Negra. En este momento ya estaría en uso el muro perimetral (García Borja y Pérez 2012: 48), aunque la muralla de Caramoro II presenta una técnica constructiva que debe relacionarse, como ya destacaron González Prats y Ruiz Segura (1992: 23), con las registradas en diversas construcciones del Bronce final del Sureste, entre ellas Penya Negra, para las que se han propuesto cronologías del siglo VIII cal BC (Lorrio 2009-2010: 154), al tiempo que se hacía mención de un fragmento de cerámica a torno de tradición fenicia (González Prats y Ruiz 1992), lo que se ha relacionado con una ocupación esporádica tras el abandono del lugar dada la ausencia de materiales de época orientalizante en las excavaciones más recientes (García Borja y Pérez 2012: 50).

Junto a Tabayá, ubicado en el umbral montañoso que separa dos cubetas en el curso medio y bajo del río Vinalopó y el asentamiento fortificado de Caramoro II, también existen evidencias de ocupaciones agrícolas en los fondos cuaternarios de la cuenca del Vinalopó y Hondo de ElcheCrevillent. Es el caso de algunas de las estructuras detectadas en la zona del Camí de Catral y El Botx (Trelis 1995; Trelis et al., 2004), en las que se desecharon una amplia variedad de objetos, especialmente, cerámicos.

\subsection{Bronce final III (850-725 cal BC)}

En cualquier caso, con independencia de que las fases anteriores se puedan mantener o puedan oscilar los periodos temporales propuestos, por el momento, creemos oportuno considerar una nueva fase arqueológica cuyos inicios deben situarse en torno al $850 \mathrm{cal} \mathrm{BC}$, al menos, para las tierras meridionales valencianas (Fig 7). Esta fase, la aquí denominada como Bronce final III, parece diferenciarse, claramente, al fundarse en estos momentos diversos núcleos cuya relación con el ámbito del mediodía peninsular es más que evidente, como ya fue puesto en consideración por diferentes autores (Llobregat 1975; Gil-Mascarell y Aranegui 1981; Arteaga 1982; González Prats 1992; Mata, Martí e Iborra 1994/96). A estos momentos parece corresponder la fundación de enclaves como Penya Negra, de forma genérica en su horizonte I (González Prats 1983; 1990), aunque no se puede descartar que su fundación pueda ser anterior, dentro del Bronce final II; la fase II de la Solana del Castell de Xàtiva (Pérez Ballester 2014: 24) a la que corresponde la documentación, en el sector E-3, de dos habitaciones absidales y de un tramo de muralla con torre, cuya edificación es posterior a las dataciones 


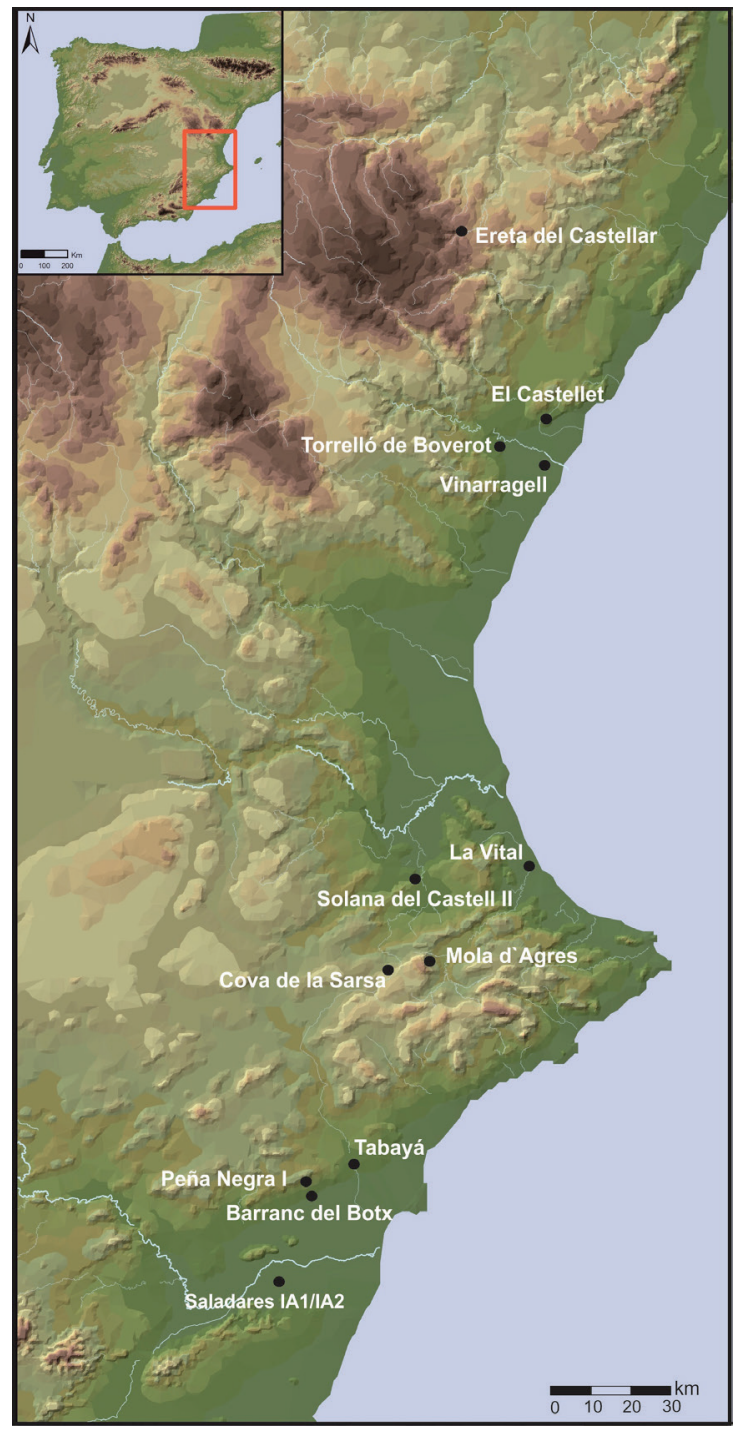

Figura 7. Mapa del este peninsular con indicación de los principales yacimientos arqueológicos del Bronce final III citados en el texto.

obtenidas de sendas muestras procedentes de los rellenos de acondicionamiento; las estructuras del Barranc del Botx (García Borja y Pérez 2012: 40-43), así como Los Saladares en su fase I-A.1 y I-A.2 (Arteaga y Serna 1975; Arteaga 1982). No obstante, esta fase también debe estar presente en parte de los yacimientos señalados anteriormente -Castellet de Nadal (Oliver, García y Moraño 2005), Torrelló de Boverot (Clausell 2004), Ereta del Castellar (Ripollés 1997), etc.-, y en otros, también de nueva planta, como Vinarragell (Mesado 1974; Mesado y Arteaga 1979), donde en su fase I se documentan las primeras edificaciones en barro, para en un segundo momento, construir muros rectilíneos sin empleo de piedra (Mata, Martí e Iborra 1994/96: 190). Del mismo modo, también podría corresponder a estos momentos, en torno al 850-800 cal BC, el abandono de Pic dels Corbs (Barrachina 2012), y probablemente de la Mola d'Agres (Peña et al., 1996).

Un asentamiento que también merece un comentario son los niveles antiguos de El Molón (Camporrobles, Valencia) para los que se dispone de una datación absoluta sobre carbón con una desviación estándar muy amplia. Se trata de un nivel del que se pudo excavar un área reducida, con niveles de relleno entre los que destacaba la abundante presencia de cerámica a mano decorada, y la única presencia de un pequeño fragmento cerámico a torno. El hecho de tratarse de rellenos de acondicionamiento y de que la muestra sea sobre una muestra de vida larga, impide precisar su adscripción cronológica, aunque claro está, la presencia de la cerámica a torno ubicaría su formación hacia momentos finales de la fase, o incluso ya en momentos iniciales del Hierro antiguo.

Por otro lado, uno de los pocos yacimientos que cuenta con una datación absoluta sobre una muestra de vida corta es Barranc del Botx (García Borja y Pérez 2012: 41. Fig. 8). De los rellenos sedimentarios que amortizaban las estructuras negativas documentadas, además de obtenerse una semilla de Triticum aestivum-durum con la que datarlas, también se recuperó un destacado repertorio cerámico. Se trata de un conjunto caracterizado por el dominio de vasos poco cuidados para labores de almacenamiento y cocina, sin decorar, y un conjunto más depurado, en ocasiones decorado, similar a los documentados en Penya Negra I y en los niveles iniciales IA1 y IA2 del sector VIII de Los Saladares (García Borja y Pérez 2012: 40-41). Entre las decoraciones, que suponen el 5,2\% del total, destaca la presencia de impresiones sobre los labios y cordones, impresiones en las paredes con relleno de pasta blanca, digitaciones en el cuerpo, incisiones y pintura. La datación obtenida sitúa la amortización de las estructuras en los inicios de esta nueva fase arqueológica, en la que ya se estaría gestando un nuevo proceso de nuclearización poblacional, cuyo máximo exponente es la fundación del gran asentamiento de Penya Negra, en dos cerros adelantados de la sierra de Crevillent.

Similares repertorios cerámicos han sido documentados en la Solana del Castell de Xàtiva en sus fases I y II, aunque en éste sí se constata 
la presencia, aunque muy escasa, de cerámicas acanaladas (Pérez Ballester 2014: 29-31), o en La Vital (García Borja et al., 2013), yacimiento situado en la línea de costa, en el que se ha documentado la presencia de cerámicas de base plana con talón, decoraciones inciso-acanaladas, impresas en el labio y engobadas, junto a una destacada actividad metalúrgica en clara relación a otros puntos costeros.

En este sentido, la mayor o menor presencia de las cerámicas acanaladas y las prácticas funerarias de cremación son dos aspectos de enorme importancia en las que no se podrá profundizar hasta que no se dispongan de nuevos registros arqueológicos. La necrópolis de Les Moreres, en su fase I (González Prats 2002) asociada a Penya Negra I, viene a mostrar la consolidación de este tipo de prácticas desde momentos avanzados del siglo IX cal BC (Lorrio 2008: 309). Esta primera fase, cuyo desarrollo fue fijado por A. González Prats (2002: 263) entre el 900 y el 725 cal BC, estaría caracterizada por la presencia de urnas tipo T1A, de cuerpos ovoides o troncocónicos invertidos, con hombros redondeados y cuellos altos, generalmente abiertos. También cuencos carenados, generalmente de carena alta (tipo T1B) y vasos de cuerpo troncocónico con hombro redondeado y amplia boca con pequeño cuello vertical (tipo T1C). El ajuar funerario está integrado por cuentas de collar en bronce y piedra, y brazaletes de bronce.

Buena parte de los asentamientos conocidos se localizan en las zonas llanas y en especial, en las llanuras litorales (Mata, Martí e Iborra 1994/96: 190-192). En este contexto, como ya se ha señalado, destaca el gran asentamiento de Penya Negra, ubicado en las estribaciones de la sierra de Crevillent, siguiendo el patrón de la Edad del Bronce, y desde el que se puede observar y controlar visualmente buena parte del litoral alicantino. Determinar el tamaño de los asentamientos es otro de los problemas de difícil resolución. En general, todos los asentamientos situados en el llano parecen ser de pequeño tamaño, mientras que Penya Negra superaría las 30 hectáreas, aunque durante el Bronce final las cabañas se distribuirían de forma dispersa por el hábitat, pero documentándose en todos los sectores ocupados con posterioridad por el poblado orientalizante, lo que da idea de la entidad del asentamiento del final de la Edad del Bronce.

Un caso parecido parece se podría plantear para otra asentamiento de gran relevancia como es la Solana del Castell de Xàtiva, ubicado en las laderas de la Serra Grossa en la confluencia de los ríos Canyoles y Albaida. Para este asentamiento, que constituye el antecedente directo del Saitabi ibero, se ha estimado una extensión superficial de unas 2 ha (Pérez Ballester, 2014: 24).

Por otro lado, las únicas evidencias estructurales conocidas son las que se han registrado en Penya Negra (González Prats 1983), Los Saladares (Arteaga y Serna 1973; 1975; 1979-80; Arteaga 1982), la Solana del Castell de Xàtiva (Pérez Ballester 2014: 24), La Vital (García Borja et al., 2013) y Barranc del Botx (García Borja et al., 2007). Mientras estos dos últimos están integrados por estructuras negativas ubicadas en el llano, en Los Saladares se pudo documentar, para sus momentos iniciales, un muro de mampostería trabada con arcillas verdosas, y en momentos más avanzados un edificio de planta rectangular, revocadas con arcillas amarillo-rojizas (Arteaga, 1982) y en la Solana de Castell, dos habitaciones absidales alargadas y un tramo de muralla con torre (Pérez Ballester 2014: 24). Penya Negra, por su parte, presenta una interesante complejidad arquitectónica documentada de forma excepcional en el sector IIE (González Prats 1990), que arranca según el autor con la presencia de fondos de cabaña, a las que se superponen cabañas circulares y continúa más tarde con casas de muros rectilíneos y esquinas redondeadas, con zócalos de piedra y arcilla, asociados a fosas con desechos de material y hornos de planta circular-oval delimitados por bloques verticales (González Prats 1983: 60).

En definitiva, el registro material de Penya Negra (González Prats 1983; 1990), Los Saladares (Arteaga y Serna 1973; 1975; 1979-80; Arteaga 1982), El Botx (García Borja et al., 2007) en la Vega Baja del Segura y de La Vital (García Borja et al., 2013) en la desembocadura del Serpis, constituyen los referentes arqueológicos de mayor calidad para caracterizar a esta fase. Se trata de un conjunto cerámico heterogéneo, con producciones poco cuidadas destinadas al almacenamiento y consumo doméstico, y una vajilla de pastas más depuradas, en su mayor parte platos y escudillas carenadas con buenos tratamientos, para el servicio de mesa, algunos de los cuales presentan decoración en sus paredes: incisiones, impresiones, excisiones, engobe y pintura (González Prats 1983; 1990; García Borja y Pérez 2012). También es muy común la presencia de bases con impresión de cestería. También están presentes los objetos de bronce, como fíbulas, punzones, cinceles, hachas, hoces y espadas, 
aunque de estos últimos sólo se hayan encontrado los moldes para su fabricación (González Prats 1990; Simón 1998; García Borja et al., 2013). El destacado trasiego comercial establecido por vía marítima es el que parece condicionar una cierta basculación poblacional hacia las zonas costeras, así como la gestación de núcleos de gran volumen poblacional e importancia política, desde donde se controlarían los procesos de intercambio y distribución de bienes (Soriano et al., 2012), siendo claros ejemplos la Solana del Castell de Xàtiva y Penya Negra. No debe extrañar, por tanto, que hacia la segunda mitad del siglo VIII cal BC se implantase en la desembocadura del Segura el asentamiento fenicio de La Fonteta (González Prats 1998; 2000).

\subsection{Hierro antiguo o fase Orientalizante (725-550 cal BC)}

Hacia mediados del siglo VIII cal BC se han determinado dos cambios de singular transcendencia para la dinámica histórica de las poblaciones del este peninsular. Por un lado, parece evidente la fundación de un asentamiento fenicio en la desembocadura del río Segura. Se trata de La Fonteta (González Prats 2000; 2010; 2011; 2014; Rouillard, Gailledrat y Sala 2007; Rouillard 2010), cuya fase más antigua se ha fechado hacia el 760-720 a.C. (González Prats 2011: 15), lo que parece confirmar una datación absoluta que remite al último tercio del siglo VIII cal BC (García Borja y Pérez, 2012: 41, fig.8), a la que habría que añadir la fundación de una posible factoría prístina en el Cabezo Pequeño del Estaño (García Menárguez 2004; Bueno, García y Prados 2013; García Menárguez y Prados 2014) hacia esas mismas fechas o un poco anteriores y su abandono hacia el tránsito del VIII al VII cal BC (Fig 8). Ambos, son yacimientos de gran transcendencia, por cuanto constituirían la puerta de entrada y salida de nuevos medios de producción y productos desconocidos hasta la fecha en estas tierras. Es el caso del instrumental de hierro, y una variada vajilla a torno, entre la que cabe destacar el amplio volumen de ánforas, normalizadas a nivel formal y volumetría, en clara relación con un interés por controlar la cantidad de lo producido y lo intercambiado.

Al mismo tiempo, o como consecuencia de su implantación, comienza a detectarse amplias transformaciones en la organización espacial y arquitectónica de los principales asentamientos indígenas, caso de Penya Negra, con su fase II

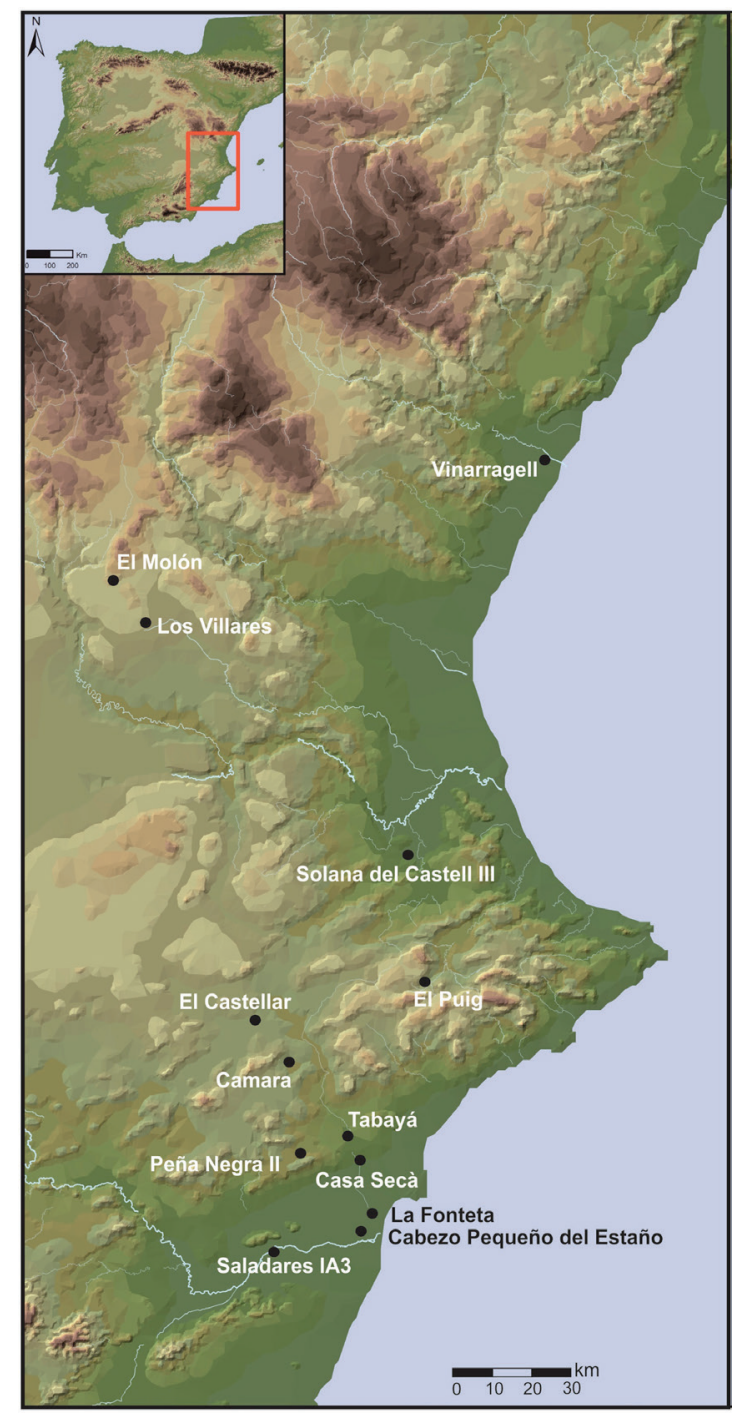

Figura 8. Mapa del este peninsular con indicación de los principales yacimientos arqueológicos del Hierro antiguo o fase Orientalizante citados en el texto.

(González Prats 1983; 2000), de Los Saladares a partir de su fase I-A3 (Arteaga 1982) o de la Solana del Castell en su fase III (Pérez Ballester 2014: 25). También se comienza a fundar un amplio número de asentamientos, tanto en altura en relación con el hinterland de Penya Negra (Moratalla 2005), como de carácter agrícola, en las mejores tierras cuaternarias del Bajo Vinalopó, caso de Casa de Secà (Soriano, Jover y López 2012) y, quizás, La Alcudia, en Elche, posiblemente ya desde el siglo VII a.C. (Moratalla 20042005: 102) 7 . Y también, el valle Medio y Alto del Vinalopó, para el que no se conoce ningún asen- 
tamiento de momentos previos, con la excepción de Tabayá, se reocupa densamente de nuevo, destacando núcleos con ocupaciones previas como El Monastil, y otros fortificados en altura, surgidos ex novo, como El Castellar de Villena o Camara (Poveda 1994).

En cualquier caso, esta fase, denominada tradicionalmente como Orientalizante o Hierro Antiguo, se ha caracterizado por la presencia generalizada en todo el ámbito del Levante peninsular de importaciones procedentes del comercio fenicio, junto a una amplia variedad y dominio de producciones cerámicas a mano (Gil-Mascarell 1981; González Prats 1983; Mata, Martí e Iborra 1994/96; Vives-Ferrándiz 2005). El número de yacimientos con esta fase arqueológica es cada vez más numeroso, encontrándose ampliamente distribuidos por todas las cuencas del Levante peninsular. Mata, Martí e Iborra (1994/96: 199, Fig. 9) ya recogían 69 yacimientos, entre núcleos al aire libre, cuevas, necrópolis y hallazgos aislados. Aunque en su mayor parte se trata de hallazgos superficiales o de antiguas intervenciones, las excavaciones efectuadas en Penya Negra (fase II), Los Saladares (fases I-A3, I-B1 y I-B2), La Fonteta, Solana del Castell (fase III) o los niveles iniciales de Vinarragell, Los Villares (Mata 1991) o, más recientemente, los de El Molón (Lorrio, Almagro-Gorbea y Sánchez 2009) o El Puig (Grau y Segura 2013: 67-95), constituyen las bases estratigráficas esenciales para caracterizar esta fase, con ciertas diferencias materiales entre los núcleos meridionales más próximos a las factorías semitas, frente a los más septentrionales. Cuestión ya abordada en profundidad en trabajos recientes (Grau Mira 2013: 259-271).

Así, como ha señalado I. Grau Mira (2013: 264), desde mediados o finales del siglo VIII cal $\mathrm{BC}$ se producirían importantes cambios en la organización territorial, al constatarse la aparición del oppidum, en torno al que se configuraría un poblamiento rural, así como áreas funerarias emplazadas en llano. Surgieron así, poblados fortificados en altura, presidiendo un patrón de asentamiento claramente jerarquizado. En torno a los oppida se distribuirían un amplio número de pequeños asentamientos rurales emplazados en el llano, algunos con carácter permanente y, otros probablemente, temporal. Los valles del Serpis constituyen un buen ejemplo del amplio número de asentamientos ubicados en el fondo de la cuenca (Grau Mira 2013: 265), al igual que otros valles más septentrionales como la Vall de Canyoles y la Foia de Xàtiva (Rodríguez y Pérez
2005). No obstante, algunos autores comienzan a señalar una tendencia de la población a concentrarse en asentamientos que con el tiempo ejercerán de centros regionales. Es el caso de La Carència de Turís, el Tossal de Sant Miquel de Llíria o Los Villares, en Caudete de las Fuentes (Bonet y Mata 2001).

El mejor ejemplo este sentido, lo constituye, sin género de dudas, el caso de Penya Negra, documentándose durante el Hierro antiguo "una extensa y regularizada ciudad orientalizante", que ya González Prats (1993: 181) identificara con acierto con la Herna del Periplo de Avieno (vv. 463), ciudad localizada en el límite septentrional de los tartessios ("hic terminus quondam stetit Tartesiorum"). Fue durante los primeros siglos de la Edad del Hierro cuando el asentamiento alcanzaría su máximo desarrollo, en gran medida por las estrechas relaciones con el núcleo fenicio de La Fonteta, localizada en la desembocadura del río Segura. La interacción social afectaron a las formas de vida y de pensamiento, dando lugar a un nuevo periodo durante el cual se produciría la introducción de la escritura, del torno de alfarero, de la metalurgia del hierro, de bronces y joyas diversas, de complementos asociados a nuevas formas de vestir como nuevos modelos de fíbulas o broches de cinturón, de collares de pasta vítrea y amuletos, entre los que se incluirían también perfumes, vajilla fina de lujo, realizada a torno y generalmente recubierta de barniz rojo, así como vino, aceite o salazones. Todos estos cambios están presentes en Penya Negra y afectarían a ámbitos tan diversos como la religión, con la llegada de nuevos dioses, o el urbanismo, evidenciado en la nueva reorganización del asentamiento, en la planta de las casas, ahora cuadrangulares con muros medianiles, o las técnicas constructivas, todo ello en relación con una creciente evolución hacia formas de vida urbana, que finalmente supuso la transformación social y política de la comunidad instalada en este importante asentamiento, en el que la presencia de fortificaciones y de un sistema de fortines que controlarían las vías de comunicación y el territorio inmediato ponen de manifiesto el papel jerarquizador de Penya Negra en la zona.

En definitiva, esta fase constituye la consolidación de una organización jerarquizada del poblamiento, políticamente dirigido, que tendrá su continuidad hasta el abandono de los importantes núcleos de Penya Negra y La Fonteta, ya entrado en siglo VI cal BC, para restructurarse nuevamente con la formación de lo reconocido como lo 'ibero'. 


\section{A modo de conclusión}

A tenor de los datos expuestos, el periodo cronológico entre el 1250 al 725 cal BC constituye una de las etapas peor caracterizadas de las tierras levantinas, por cuanto las bases estratigráficas asociadas a dataciones absolutas sobre muestras de vida corta son muy escasas. Hasta el momento, las secuencias estratigráficas de larga ocupación que sirven de base para caracterizar estos momentos se reducen a cuatro asentamientos: Cabezo Redondo para los momentos previos a 1300/1250 cal BC, Pic dels Corbs para el periodo $1300-800$ cal BC, Penya Negra para la etapa del 850-550 cal $\mathrm{BC}$, a los que hay que sumar los primeros datos de la secuencia de la Solana del Castell (Pérez Ballester 2014).-

La información aportada por estos asentamientos, se complementa con la aportada por otros núcleos peor conocidos, de carácter monofásico -l'Arbocer-Altet de Palau, Costamar, La Vital y Caramoro II- o con más fases de ocupación -El Negret, Torrelló de Boverot, El Castellet-, aunque las escasas dataciones absolutas o, su total ausencia, no ha facilitado el establecimiento de una periodización sólidamente construida. Las falta de secuencias datadas y seriadas ampliamente, dificultan diferenciar a qué momento pertenecen determinadas ocupaciones detectadas en numerosos yacimientos, en especial, entre el Bronce tardío y el Bronce final I.
En el presente trabajo, y a modo de ensayo, se ha presentado una propuesta de fasificación, de carácter generalista, con el fin de contribuir a la ordenación de un registro cada vez más amplio, aunque con bases estratigráficas y cronológicas todavía endebles. Se ha establecido una diferenciación en 4 grandes fases arqueológicas para el periodo comprendido entre el 1500 y el $725 \mathrm{cal}$ BC -Bronce tardío, final I, final II y final III- a partir de los cambios detectados en la ocupación de los asentamientos excavados hasta la fecha, acompañados en muchos momentos, de reorganizaciones en el territorio. A partir de mediados del siglo VIII a.C., con la presencia estable de población de origen semita en la desembocadura del río Segura, ya se iniciaría la primera de las fases del Hierro antiguo u orientalizante.

Para finalizar, creemos oportuno insistir en el hecho de que si se pretende profundizar en el estudio del proceso histórico de aquellas sociedades, será necesario emprender proyectos de excavación que, además de contemplar los procesos de formación y transformación de los contextos arqueológicos, fije con precisión el desarrollo de ocupación de los mismos, apoyado en un buen número de dataciones absolutas sobre muestras de vida corta. De lo contrario, el periodo temporal entre la segunda mitad del II milenio y la primera mitad del I cal BC, seguirán siendo el periodo más oscuro de toda la Prehistoria reciente en las tierras del Levante peninsular.

\section{Notas}

1. Este trabajo se ha realizado dentro del marco del proyecto del Ministerio de Economía y Competitividad HAR2013-41447-P "El Bronce Final y la Edad del Hierro en el Sureste y el Levante de la Península Ibérica: procesos hacia la urbanización".

2. En los últimos años también se han iniciado actuaciones arqueológicas en l'Arborcer-Altet de Palau (García Borja y De Pedro 2013), Ereta del Castellar-bajo la dirección de M. J. de Pedro y E. Ripollés-, El Negret (Barciela et al., 2012), la Solana del Castell de Xàtiva (Pérez Ballester 2014), y, desde 2014, en Penya Negra, dirigidas por A. J. Lorrio Alvarado.

3. Todas las calibraciones han sido realizadas con el programa OxCal v4.2.3. (Bronk Ramsey y Lee 2013), utilizando la curva de calibración Intcal13 (Reimer et al., 2013).

4. La serie de dataciones absolutas de Cabezo Redondo supera la veintena (Hernández 2009; 2012). Mientras nueve de ellas se ubicarían en la franja cronológica entre el 1500 y el 1250 cal BC, el resto corresponden a la fase de ocupación anterior, entre 1750 y 1500 cal BC (Jover, López Padilla y García Donato, 2014).

5. Son 17 las dataciones absolutas publicadas de Orpesa la Vella (Gusi y Olària 2014: 260, Tabla 63). De ellas, solamente 2 corresponden a los momentos finales de la ocupación prehistórica.

6. Agradecemos a Fernando Prados Martínez que nos haya facilitado las dos dataciones efectuadas en el asentamiento del Cabezo Pequeño del Estaño, todavía inéditas. También a Juan Antonio López Padilla y Sergio Martínez Monleón, su apoyo en el tratamiento de las dataciones absolutas. 
7. En relación con estas ocupaciones estaría probablemente el hallazgo de un importante depósito de "lingotes-hacha" (González Prats 1985b; Renzi 2010), encontrados a finales del siglo XIX en "los campos de Ilici" y que a menudo se han vinculado con La Alcudia, aunque tal asociación no esté demostrada (Hernández 2005: 28).

\section{Biblografía}

Abarquero Moras, F. J. (2005): Cogotas I, la difusión de un tipo cerámico durante la Edad del Bronce. Arqueología en Castilla y León, 4. Junta de Castilla y León, Valladolid.

Acosta Pradillos, L. y López Padilla, J.A. (2012): Apuntes sobre la ocupación de la Cova d'en Pardo durante la Edad del Bronce. En Soler Díaz 2012: 287-297. [ya que la obra colectiva editada por J.A. Soler Díaz está citada en la lista].

Arteaga Matute, O. (1982): Los Saladares-80. Nuevas directrices para el estudio del horizonte protoibérico en el Levante Meridional y Sudeste de la península Ibérica. Huelva Arqueológica, VI: 13-183.

Arteaga Matute, O.; Serna, M. R. (1973): Los Saladares. Un yacimiento protohistórico en la región del Bajo Segura. XII Congreso Nacional de Arqueología, (Jaén, 1971), Zaragoza: 437-450.

Arteaga Matute, O.; Serna, M.R. (1975): Los Saladares-71. Noticiario Arqueológico Hispánico, Arqueología 3: 7-140.

Arteaga Matute, O.; Serna, M.R. (1979-80): Las primeras fases del poblado de Los Saladares (Orihuela, Alicante). Una contribución al estudio del Bronce Final en la Península Ibérica (estudio crítico 1). Ampurias, 41-42: 65-137.

Barciela Gónzalez, V.; Hernández Pérez, M.s.; López Seguí, E.; Torregrosa Giménez, P. (2012): A medio camino. Excavaciones arqueológicas en El Negret (Agost, Alicante). Marq. Arqueología y Museos, 5: 103-131.

Barrachina IbÁÑ̃z, A. M. (1987): El bronze final en el poblat del Puig d'Alcoi. Fonaments. Prehistòria $i$ mon antic al Països Catalans, 6: 131-155.

Barrachina IbáÑez, A. M. (1999): El "sector S" del Pic dels Corbs de Sagunt: materiales cerámicos de la fase final de su ocupación: campañas de 1990 y 1991. Archivo de Prehistoria Levantina, 23: 209-232.

BarRachina IbÁÑEz, A. M. (2009): Nuevos datos para el estudio del final de la Edad de Bronce en las comarcas septentrionales valencianas: la fase III del Pic dels Corbs de Sagunt. Quaderns de Prehistòria i arqueología de Castelló, 27: 41-62.

BARRACHINA IBÁÑEz, A. M. (2012): Indesinenter: permanencia y cambio. El Pic dels Corbs como modelo de interpretación de la edad del bronce en el norte del País Valenciano. Serie de Prehistòria i Arqueología, Servei d'Investigacions Arqueològiques i Prehistòriques, Diputació provincial, Castelló de la Plana.

Barrachina Ibáñez, A.; Gusi Jener, F. (2004): Primeros resultados del estudio cerámico de las fases del Bronce tardío y final de Orpesa la Vella (Orpesa, Catelló). La Edad del Bronce en las tierras valencianas y zonas limítrofes, (L. Hernández y M.S. Hernández, eds.), Instituto de Cultura Juan Gil-Albert, Ayuntamiento de Villena, Villena: 137-146.

Belmonte Mas, D. (2004): Un conjunto cerámico del Bronce tardío e inicios del Bronce Final del yacimiento de Tabayà (Aspe, Alicante). Excavaciones arqueológicas de 1987 a 1991.Corte estratigráfico 11. La Edad del Bronce en tierras valencianas y zonas limitrofes, (L. Hernández y M.S. Hernández, eds.), Instituto de Cultura Juan Gil-Albert, Ayuntamiento de Villena, Villena: 333-345.

Bonet, E.; Garibo, J.; Guérin, P.; Mata, C.; Valor J.P.; Vives-Ferrándiz, J. (2004): Las ánforas importadas de las comarcas centrales del País Valenciano. La circulació d'àmfores al Mediterrani occidental durant la Protohistòria (segles VIII-III a.C.): aspectos quantitatius $i$ análisis de continguts. Actes de la II Reunió Internacional d'Arqueologia de Calafell, Arqueomediterránea, 8, Universidad de Barcelona, Barcelona: 203-227.

Bonet, E.; Mata, C. (2001): Organización del territorio y poblamiento en el País Valenciano entre los ss. VII y II a.C. Entre Celtas e Iberos. Las poblaciones prehistóricas de las Galias e Hispania. (L. BerrocalRangel y Ph. Gardes, eds.), Biblitheca Archaeologica Hispana, 8, Madrid: 175-186.

Bosch Gimpera, P. (1932): Etnología de la Península Ibérica. Alpha, Barcelona. 
Bronk Ramsey, C. Y Lee, S. (2013): Recent and Planned Developments of the Program OxCal. Radiocarbon, 55(2-3): 720-730.

Bueno, P.; García Menárguez, A.; Prados, F. (2013): Murallas fenicias en Occidente. Una valoración conjunta de las defensas del Cerro del Castillo (Chiclana, Cádiz) y del Cabezo Pequeño del Estaño (Guardamar, Alicante). Heracleion, 6: 27-75.

Clausell, G. (2004): El Torrelló del Boverot: del Bronce Medio al comienzo del Hierro. La Edad del Bronce en tierras valencianas y zonas limitrofes (L. Hernández y M.S. Hernández, eds.), Instituto de Cultura Juan Gil-Albert, Ayuntamiento de Villena, Villena: 167-176.

Castro, P.; Chapman, R.w.; Gili, S.; Lull, V.; Micó, R.; Rihuete, C.; Risch, R.; Sanahuja, E. (1999): Proyecto Gatas 2. La dinámica arqueoecológica de la ocupación prehistórica, Conserjería de Cultura, Sevilla.

Castro, P.; Lull, V.; Micó, R. (1996): Cronología de la Prehistoria Reciente de la Península Ibérica y Baleares (c. 2800-900 cal ANE). BAR International Series 652, Oxford.

De Pedro Michó, M. J. (1998): La Lloma de Betxí (Paterna, Valencia). Un poblado de la Edad del Bronce. Serie de Trabajos Varios del Servicio de Investigación Prehistórica, 94, Valencia.

De Pedro Michó, M.J. (2002): El poblado de la Edad del Bronce. El Puntal del Llops. Un fortín edetano, (H. Bonet y C. Mata, coords.), Serie de Trabajos Varios del Servicio de Investigación Prehistórica, 99, Diputación provincial, Valencia.

De Pedro Michó, M. J. (2004): La Cultura del Bronce Valenciano: consideraciones sobre su cronología y periodización. La Edad del Bronce en tierras valencianas y zonas limitrofes, (L. Hernández y M.S. Hernández, eds.), Instituto de Cultura Juan Gil-Albert, Ayuntamiento de Villena, Villena: 41-57.

Enguix, R. (1980): La Edad del Bronce. Nuestra Historia, I: 151-170. Valencia.

Enguix, R.; MARTí, B. (1988): La Cultura del Bronce Valenciano y la Muntanya Assolada de Alzira: aproximación al estado actual de su investigación. Archivo de Prehistoria Levantina, XVIII: 241-250.

Flors, E. (coord) (2010): Torre la Sal (Ribera de Cabanes, Castellón). Evolución del paisaje antrópico desde la prehistoria hasta el Medioevo. Monografies de Prehistòria i Arqueologia Castellonenques, 8. Diputació Provincial, Castelló.

García Borja, P.; Carrión, Y.; Carolina, P.; Iborra, P.; López, D.; Miret, C., Montero, I.; Pascual, J. Ll.; Pérez, G.; Rovira, S.; Valero, A.; Vives-Ferrándiz, J. (2013): Nuevas aportaciones al horizonte del Bronce final de La Vital (Gandía, València). Saguntum, 45: 79-100. Doi: 10.7203/SAGVNTVM.

García Borja, P.; Carrión, Y.; Collado, I.; Montero, I.; Muñoz, M.; Pérez, G.; Roldán, C.; Román, D.; Tormo, C.; Verdasco, C.; Vives-Ferrándiz, J. (2010): Campaña de excavación arqueológica de urgencia en Caramoro II (Elx, Alacant). Marq, Arqueología y museos, 4: 37-66.

García Borja, P.; De Pedro, M.j. (2013): El conjunt arqueològic de l'Edat del Bronze de l'Arborcer-Altet de Palau (La Font de la Figuera, València). El naixement d'un poble. Historia i arqueología de la Font de la Figuera, (P. García Borja; E. Revert; A. Ribera, A. y V. Biosca, eds.), Ajuntament de La Font de la Figuera, La Font de la Figuera: 61-72.

García Borja, P.; De Pedro, M.j.; Sánchez, A. (2005): Conjunto de materiales procedentes del poblado de la Edad del Bronce de l'Arborcer (La Font de la Figuera, Valencia). Trabajos de Prehistoria, 62,1: 181-191.

García BorJa, P.; Pérez JordÀ, G. (2012): Ensayo tipológico para el estudio de cerámica prehistórica del País Valencià. Aplicación a colecciones del Bronce final. Lvcentum, XXXI: 31-59.

García Borja, P.; Salazar-García, C.; Martins, H.; Pérez, G.; Sanchis, A. (2012): Dataciones radiocarbónicas de la Cova de la Sarsa (Bocairent, València). Recerques del Museo d'Alcoi, 21: 19-24.

García Borja, P.; Verdasco, C.; Muñoz, M.; Carrión, Y.; Pérez, G.; Tormo, C.; Trelis, J. (2007): Materiales arqueológicos del Bronce final aparecidos junto al Barranc del Botx (Crevillent, Alacant). Recerques del Museu d'Alcoi, 16: 89-112.

García Menárguez, A. (1994): El Cabezo Pequeño del Estaño, Guardamar del Segura. Un poblado protohistórico en el tramo final del río Segura. El mundo púnico. Historia, sociedad y cultura, (A. González; J.L. Cunchillos y M. Molina, eds.), Coloquios de Cartagena, I, Cartagena: 269-280. 
García Menárguez, A.; Prados, F. (2014): La presencia fenicia en la península Ibérica: El Cabezo Pequeño del Estaño (Guardamar del Segura, Alicante). Trabajos de Prehistoria, 71,1: 113-133. Doi: 10.3989/ tp.2014.12127

Gil-Mascarell, M. (1980): El poblado de la Mola d'Agres. Dos cortes estratigráficos. Saguntum, 16: 7590.

Gil-Mascarell, M. (1981): Bronce Tardío y Bronce Final en el País Valenciano. En M. Gil-Mascarell y C. Aranegui 1981: 9-39.

Gil-Mascarell, M. (1983): El poblado de la Edad del Bronce de la Mola d'Agres (Agres, Alicante). Congreso Nacional de Arqueología, XVI, Zaragoza: 269-276.

Gil-Mascarell, M. (1984): El bronze final i l'inici del procés d'iberizació al País Valencià. Fonaments, 4: 11-29.

Gil-Mascarell, M. (1985): El final de la Edad del Bronce: Estado actual de la investigación. Arqueología del País Valenciano: Panorama y perspectivas (M.S. Hernández, eds.), Universidad de Alicante, Alicante: $141-153$.

GiL-Mascarell, M. (1992): La agricultura y la ganadería como vectores económicos del desarrollo del Bronce Valenciano. Saguntum, 28: 63-73.

Gil-Mascarell, M. (1995): Algunas reflexiones sobre el Bronce Valenciano. Saguntum, 28: 63-73.

Gil-Mascarell, M.; Aranegui Gascó, C. (1981): El Bronce Final y los comienzos de la Edad del Hierro en el País Valenciano. Papeles del Laboratorio de Arqueología de la Universidad de Valencia, 1, Valencia.

Gil-Mascarell, M.; Peña, C. (1994): Las fases de ocupación en el yacimiento de la Mola d'Agres (Agres, Alicante). Recerques del Museu d'Alcoi, 3: 101-113.

GonzÁlez Prats, A. (1977-78): $1^{\circ}$ resultados de las excavaciones realizadas en el yacimiento protohistórico de la Peña Negra, Crevillente, Alicante. Pyrenae, 13-14: 121-135.

GonzÁlez Prats, A. (1983): Estudio arqueológico del poblamiento antiguo de la sierra de Crevillente (Alicante). Anejo I de la revista Lvcentum, Universidad de Alicante, Alicante.

González Prats, A. (1985a): Los nuevos asentamientos del final de la Edad del Bronce. Problemática cultural y cronológica. Arqueología del País Valenciano: panorama y perspectivas, Anejo de la revista Lucentum, Alicante: 153-184.

GonzÁlez Prats, A. (1985b): Sobre unos elementos materiales del comercio fenicio en tierras del Sudeste peninsular. Lucentum, IV: 97-106.

GonzÁlez Prats, A. (1998): La Fonteta, 1997. Memoria preliminar de la $2^{\mathrm{a}}$ campaña de excavaciones ordinarias en la ciudad fenicia de la desembocadura del río Segura, Guardamar (Alicante). Actas del I Seminario Internacional sobre temas fenicios. La cerámica fenicias en Occidente: centros de producción y áreas de comercio (Guardamar del Segura, 1997), Alicante: 257-301.

GonzÁlez Prats, A. (1990): Nueva luz sobre la protohistoria del Sudeste. Universidad de Alicante, Alicante.

GonzÁlez Prats, A. (1992): El proceso de formación de los pueblos ibéricos en el Levante y Sudeste de la península Ibérica. Complutum, 2-3: 137-150.

GonzÁlez Prats, A. (2000): Fenicios e indígenas en el Levante peninsular. Fenicios e indígenas en el mediterráneo y occidente: modelos e interacción. Actas de los Encuentros de Primavera de la Universidad de Cádiz en el Puerto de Santa María, 1998, El Puerto de Santa María: 107-118.

González Prats, A. (2002): La necrópolis de cremación de Les Moreres (Crevillente, Alicante, España) (s. $I X$-VII a.C.). Universidad de Alicante, Alicante.

GonzÁlez Prats, A. (2010): La presencia fenicia en el Bajo Segura. Guardamar del Segura. Arqueología $y$ museos, MARQ, Alicante: 58-65

GonzÁlez Prats, A. (2011): La Fonteta. Excavaciones de 1996-2002 en la colonia fenicia de la actual desembocadura del río Segura (Guardarmar de Segura, Alicante), Vol. 1. Seminarios Internaciones sobre Temas Fenicios, Alicante.

GonzÁlez Prats, A. (2014): La Fonteta (Guardamar de Segura, Alicante). t. 2.1 y 2.2. Universidad de Alicante, Alicante. 
González Prats, A.; Ruiz Segura, E. (1992): Caramoro II: un poblado fortificado del Bronce Final en el Bajo Vinalopó. Serie de Trabajos Varios del Servicio de Investigación Prehistórica, 89. Homenaje a Enrique Pla Ballester, Diputación Provincial, Valencia: 17-27.

Grau Mira, I. (2013): Síntesis: El Puig y el paisaje de los Oppida en las comarcas de las montañas de la Contestania. En Grau y Segura 2013:259-290.Grau Almero, E.; Martí Bonafé, M. A.; Peña Sánchez, J. L.; Pascual Benito, J. L.; Pérez JordÁ, G.; López Gila, M. D. (2004): Nuevas aportaciones para el conocimiento de la Mola d'Agres (Agres, Alicante). La Edad del Bronce en tierras valencianas y zonas limitrofes, (L. Hernández y M.S. Hernández, eds.), Instituto de Cultura Juan Gil-Albert, Ayuntamiento de Villena, Villena: 241-246.

Grau Mira, I.; Segura, J.m. (2013): El oppidum ibérico de El Puig d'Alcoi. Asentamiento y paisaje en las montañas de la Contestania. Museu Arqueològic, Alcoi.

Gusi Jener, F. (1974): Excavación en el recinto fortificado del Torrelló de Onda. Cuadernos de Prehistoria y Arqueología Castellonense, 1: 19.

Gusi Jener, F. (1975): Las dataciones de C.14 de la Cueva del Mas d'Abad (Coves de Vinromà). Campaña 1975. Ensayo cronológico para la periodización del Bronce Valenciano. Cuadernos de Prehistoria y Arqueología Castellonense, 2: 75-79.

Gusi Jener, F. (1976): $1^{\text {a }}$ Campaña de excavaciones en el poblado del Bronce de Oropesa la Vella (Orpesa). Cuadernos de Prehistoria y Arqueología Castellonense, 3: 283.

Gusi Jener, F.; Olaría, C. (1977): El poblado de la Edad del Bronce de Orpesa la Vella (Castellón). Cuadernos de Prehistoria y Arqueología de Castellón, 4: 79-100.

Gusi Jener, F.; Olària, C. (1995): Cronologies absolutes en l'arqueologia del País Valencià. Actes de les jornades d'Arqueologia, (R. Enguix, coord.), Conselleria de Cultura, Generalitat Valenciana, Alfás del Pi: $119-149$.

Gusi, F.; Olaría, C. (2014): Un poblado fortificado del Bronce medio y Bronce final en el litoral Mediterráneo: Orpesa la Vella (Orpesa la Vella, Castellón, España). Monografies de Prehistòria i Arqueologia Castellonenques 10, Diputació de Castelló, Castelló.

Gusi, F.; Luján, J.; Barrachina, A.; Aguilella, G. (2010): Aproximación al estudio del poblamiento litoral-costero durante la Edad del Bronce en la fachada oriental de la Península Ibérica y del Mediodía francés. Cuadernos de Prehistoria y Arqueología de Castellón, 28: 59-138.

Hernández Pérez. M.S. (1994): La Horna (Aspe, Alicante). Un yacimiento de la Edad del Bronce en el Medio Vinalopó". Archivo de Prehistoria Levantina, XXI.: 83-116. Valencia.

Hernández Pérez, M. S. (1997): Espacio y tiempo en la Edad del Bronce del País Valenciano. Espacio, tiempo y forma. Serie I, Prehistoria y Arqueología: 279-316.

HernÁndez PÉREZ, M. S. (2001): La Edad del Bronce en Alicante. Y acumularon tesoros... Mil años de historia en nuestras tierras, (M.S. Hernández Pérez, ed.), Caja de Ahorros del Mediterráneo, Alicante: 201-217.

Hernández Pérez, M. S. (2005): La Contestania Ibérica desde la Prehistoria. La Contestania Ibérica, treinta años después, (L. Abad; F. Sala e I. Grau, eds.), Universidad de Alicante, Alicante: 17-36.

Hernández Pérez, M. S. (2009): Tiempos de cambio. El final del Argar en Alicante. En los confines del Argar. Una cultura de la Edad del Bronce en Alicante, (M.S. Hernández; J.A. Soler y J.A. López, eds.), MARQ, Alicante: 292-305.

Hernández Pérez, M.S. (2012): El Cabezo Redondo (Villena, Alicante) y el Bronce Tardío en las tierras meridionales valencianas. En Cogotas I: La cultura de la Edad del Bronce en la Península Ibérica, (J.A. Rodríguez Marcos y J. Fernández Manzano, eds.), Universidad de Valladolid, Valladolid: 111-146.

Hernández Pérez, M.s.; Jover Maestre, F.J.; López Padilla, J.A. (2013): The social and political situation between 1750 and $1500 \mathrm{cal} \mathrm{BC}$ in the central Spanish Mediterranean: an archaeological overview. 1600 Cultural change in the shadow of the Thera-Eruption?, (H. Meller; F. Bertemes; H.R. Bork y R. Risch, eds.), Tagunden des Landmuseums für Vorgeschichte Halle, band 9, Halle: 303-314.

Hernández Pérez, M.s.; García Atiénzar, G.; Barciela González, V., Lillo Bernabeu, M. Y MartoRell Briz, X. (2012): Cabezo Redondo (Villena, Alicante). Caracterización de "espacios domésticos" en un poblado del Bronce Tardío. Campañas de 2010 a 2012. II Jornadas de Arqueología y Patrimonio Alicantino. Arqueología en Alicante en la primera década del siglo XXI. MARQ, Arqueología y museos, Extra 01, Alicante: 215-221. 
Hernández Pérez, M.s.; López Mira, J.A. (1992): Bronce Final en el Medio Vinalopó. A propósito de dos conjuntos cerámicos del Tabaià (Aspe, Alicante). Trabajos Varios del Servicio de Investigación Prehistórica, 89, Diputación provincial, Valencia: 1-15.

Hernández Pérez, M.s.; Pérez Burgos, J.M. (2005): En busca de nuestros orígenes. El poblamiento prehistórico de Sax. Historia de Sax, I. Ayuntamiento de Sax, Sax: 103-128.

Jover Maestre, F. J. (1999): Una nueva lectura del "Bronce Valenciano”. Universidad de Alicante, Alicante.

Jover Maestre, F.J. (2006): La ocupación prehistórica en el valle de Elda. Historia de Elda, Tomo I, (A.M. Poveda y J.R. Valero, coords.), Ayuntamiento de Elda, Elda: 29-43.

Jover Maestre, F. J.; López Padilla, J. A. (2004): 2110- 1200 BC. Aportaciones al proceso histórico en la cuenca del río Vinalopó. La Edad del Bronce en tierras valencianas y zonas limitrofes, (L. Hernández y M.S. Hernández, coords.), Instituto de Cultura Juan Gil-Albert, Ayuntamiento de Villena, Villena: 285302.

Jover Maestre, F.J.; López Padilla, J.A. (2009): Más allá de los confines de El Argar: los inicios de la Edad del Bronce y la delimitación de las áreas culturales en el cuadrante sur-oriental de la península Ibérica, 60 años después. En los confines del Argar. Una cultura de la Edad del Bronce en Alicante. (M.S. Hernández; J. Soler, J. y J.A. López, coords.), Museo Arqueológico de Alicante, Alicante: 268-291.

Jover Maestre, F. J.; López Padilla, J. A. (2011): La observación en el estudio de la edad del bronce en tierras valencianas. Del ensalzamiento del "objeto" y la revolución radiocarbónica al necesario reencuentro con la estratigrafía. Cuadernos de Prehistoria y Arqueología de Castellón, 29:209-230. Castellón.

Jover Maestre, F.J.; López Padilla, J.A.; García-Donato, G. (2014): Radiocarbono y estadística bayesiana: aportaciones a la cronología de la Edad del Bronce en el extremo oriental del Sudeste de la península Ibérica. Sagvntvm, 46: 41-69. Doi: 10.7203/SAGVNTVM.46.3479

López CAChero, F.J. (2007): Sociedad y economía durante el Bronce final y la primera Edad del Hierro en el Noreste peninsular: una aproximación a partir de las evidencias arqueológicas. Trabajos de Prehistoria, 64, 1: 99-120. doi:10.3989/tp.2007.v64.i1.

López Cachero, F.J. (2008): La periodidització del Bronze Final al Ferro inicial a Catalunya. Cypsela, 17: 51-64.

López CACHero, F.J. (2011): Cremation cementeries in the Northeastern Iberian Peninsula: funeral diversity and social transformation during the Late Bronze and Iron Ages. European Journal of Archaeology, 14, 1-2: 116-132.

López Padilla, J.A. (2009): El grupo argárico en los confines orientales del Argar. En los confines del Argar. Una cultura de la Edad del Bronce en Alicante. En M.S Hernández, J.A. Soler Díaz y J.A. López Padilla (coords.), Museo Arqueológico Provincial de Alicante, Alicante: 247-267.

López Padilla, J.A. (2011): Asta, hueso y marfil. Artefactos óseos de la Edad del Bronce en el Levante y Sureste de la península Ibérica (c. 2500-c. 1300 cal BC). Serie Mayor 9, MARQ, Museo Arqueológico Provincial, Alicante.

Lorrio Alvarado, A. (2008): Qurénima: El Bronce Final del sureste de la península Ibérica. Bibliotheca Archaeologica Hispanica, 27, Madrid.

Lorrio Alvarado, A. J. (2009-2010): El Bronce Final en el Sureste de la península Ibérica: una (re)visión desde la arqueología funeraria, Anales de Prehistoria y Arqueología, Universidad de Murcia, 25-26, 2012: 119-176.

Lorrio Alvarado, A. J., Almagro-Gorbea, M. Y Sánchez De Prado, M. a D. (2009): El Molón (Camporrobles, Valencia). Oppidum prerromano y hisn islámico. Guía turística y arqueológica, Real Academia de la Historia, Camporrobles.

Llobregat Conesa, E.A. (1973): Del fin del Neolítico de las cerámicas impresas al comienzo de la Edad del Bronce en la región valenciana. Papeles del Laboratorio de Arqueología de Valencia, 9: 3-10.

Llobregat Conesa, E.A. (1975): Nuevos enfoques para el estudio del periodo del Neolítico al Hierro en la región valenciana. Papeles de Laboratorio de Arqueología de Valencia, 11: 119-140.

Llobregat Conesa, E.A. (1986): Illeta dels Banyets. Arqueología en Alicante 1976-86: 63-67. Alicante. 
Lull, V.; Micó, R.; Risch, R.; Rinuete, C. (2009): El Argar: la formación de una sociedad de clases. En Hernández, M.S., Soler J. y López, J.A., En los confines del Argar. Una cultura de la Edad del Bronce en Alicante (M.S. Hernández; J.A. Soler y J.A. López, coords.), MARQ, Alicante: 224-245.

Lull, V., Micó, R., Rinuete, C.; Risch, R. (2011): El Argar and the beginning of Class society in the Western Mediterranean. Sozialarchäologische perspektiven: Gesselschaftlicher wandel 5000-1500 v. Chr. zwischen Atlantik und Kaukasus, (S. Hansen, J. Müller, eds.), Dëutsches Archäologisches Institut, Berlin: 381-414.

Lull, V.; Micó, R.; Rinuete, C.; Risch, R. (2013): Political collaps and social change at the end of El Argar. En Meller, H., Bertemes, F., Bork, H.R. y R. Risch, (Eds.), 1600 Cultural change in the shadow of the Thera-Eruption?, (H. Meller; F. Bertemes; H.R. Bork y R. Risch, eds.), Landesmuseum für Vorgeschichte, 9, Halle: 283-302.

Martí Oliver, B.; Bernabeu, J. (1992): La Edad del Bronce en el País Valenciano. Aragón/ Litoral Mediterráneo. Intercambios culturales durante la Prehistoria, Instituto Fernando El Católico, Zaragoza: 555-567.

Mata Parreño, C. (1991): Los Villares (Caudete de las Fuentes, Valencia): origen y evolución de la Cultura Ibérica. Trabajos Varios del Servicio de Investigación Prehistórica, 88. Diputación provincial, Valencia.

Mata, C., Martí, Ma A. E Iborra, Má, P. (1994-96): El País Valencià del Bronce recent a l'Ibéric antic: el procés de formació de la societat urbana ibèrica. Models d'ocupació, transformació i explotació del territori entre el 1600 i el 1500 A.N.E. a la Catalunya Meridional i zones limítrofes de la Depressió de l'Ebre, (J. Rovera, ed.). Gala, 3-5: 183-218.

McClune, S.b.; García, O.; Roca De Togores, C.; Culleton, B.J.; Kennett, D.J. (2011): Osteological and paleodietary investigation of burials from Cova de la Pastora, Alicante, Spain. Journal of Archaeological Science, 38: 420-428.

Mesado Oliver, N. (1974): Vinarragell (Burriana, Castellón). Trabajos Varios del Servicio de Investigación Prehistórica, 46. Diputación provincial, Valencia.

Mesado Oliver, N. (2005): La Cova de Les Bruixes (Rosell, Castellón). Trabajos Varios del Servicio de Investigación Prehistórica, 105. Diputación provincial, Valencia.

Mesado, N.; Arteaga, O. (1979): Vinarragell (Burriana, Castellón), II. Trabajos Varios del Servicio de Investigación Prehistórica, 61. Diputación provincial, Valencia.

Molina GonzÁlez, F. (1978): Definición y sistematización del Bronce Tardío y Final en el Sureste de la Península Ibérica. Cuadernos de Prehistoria y Arqueología de la Universidad de Granada, 3: 159-232.

Molina MAs, F. (1999): La cerámica del Bronce Tardío e inicios del Bronce Final en el valle medio del río Vinalopó: el ejemplo del Tabayá (Aspe, Alicante). Revista d'Arqueologia de Ponent, 9: 117-130.

Moratalla Jávega, J. (2005): El territorio meridional de la Contestania. La Contestania Ibérica, treinta años después, (L. Abad; F. Sala e I. Grau, eds.), Anejo a la revisa Lucentum, 13, Universidad de Alicante, Alicante: 91-117.

Navarro Mederos, J.F. (1982): Materiales para el estudio de la Edad del Bronce en el Valle Medio del Vinalopó (Alicante). Lvcentvm, II: 19-70.

Oliver, A.; García, J.m.; Moraño, I. (2005): El Castellet, Castelló de la Plana. Yacimiento emblemático en la historiografia de la Edad del Bronce peninsular. Fundación Dávalos-Fletcher, Castellón.

Palomar, V. (1990-91): Las dataciones de C-14 de la cueva del Murciélago (Altura, Alto Palància). Cuadernos de Prehistoria y Arqueologia Castellonense, 15: 437-442.

Peña Sánchez, J.l.; Enrique, M.; Grau, E.; Martí, M. (1996): El poblado de la Mola d'Agres. Homenaje a Milagros Gil-Mascarell Boscà. Generalitat Valenciana, Valencia.

Pernas García, S. (2012): Las cuevas de enterramiento del Bronce final. Mundo funerario en los valles del Vinalopó y Serpis. Fundación José María Soler de Villena, 20, Villena.

Pérez Ballester, J. (2014): Entre el Bronce final y el Hierro antiguo. Las cerámicas a mano de la Solana del Castell (Xàtiva, València). Lvcentvm, XXXIII: 23- 39. Doi: 10.14198/LVCENTVM2014.33.02

Picazo, J.v.; Rodanés, J.m. (coord.) (2009): Los poblados del Bronce Final y primera Edad del Hierro. Cabezo de la Cruz. La Muela. Zaragoza. Gobierno de Aragón, Departamento de Educación, Cultura y Deporte, Zaragoza. 
Pons E. (2012): Les necrópolis d'incineració en el Nord-Est català (1100-550 ANE): una nova sintesí. Les necrópolis d'incineració entre l'Ebre i el Tiber (segles IX-VI aC). Metodología, practiques funeràries $i$ societat, (M.C. Rovira; F.J. López Cachero y F. Mazière, eds.), Barcelona: 57-74.

Poveda Navarro, A. M., (1994): La fase del Hierro antiguo y la influencia fenicia en la cuenca interior del Vinalopó (Alicante). Alebus, 4-5: 49-71.

Puigcerver Hurtado, A. (1992-94): Arqueología de la Edad del Bronce en Alicante: La Horna, Foia de la Perera y Lloma Redona. Lucentum, XI-XIII: 63-72.

Puigcerver Hurtado, A.; López Padilla, J.A. (2005): Caza y ganadería durante la Edad del Bronce en el Alto Vinalopó. La fauna de la Peña. Historia de Sax, vol. I, Sax: 133-139.

Reimer, P. J., Bard, E., Bayliss, A., Beck, J. W., Blackwell, P. G., Bronk Ramsey, C., Buck, C. E., Cheng, H., Edwards, R. L., Friedrich, M., Grootes, P. M., Guilderson, T. P., Haflidason, H., Hajdas, I., Hatté, C., Heaton, T. J., Hoffmann, D. L., Hogg, A. G., Hughen, K. A., Kaiser, K. F., Kromer, B., Manning, S. W., Niu, M., Reimer, R. W., Richards, D. A., Scott, E. M., Southon, J. R., Staff, R. A., Turney, C. S. M. Y Van Der Plicht, J. (2013): IntCal13 and Marine13 Radiocarbon Age Calibration Curves 0-50,000 Years cal BP. Radiocarbon, 55 (4): 1869-1887.

RenZI, M. (2010): La producción de "lingotes-hacha" en el Levante peninsular: nueva valoración a partir de los materiales de la Fonteta (Guadamar del Segura, Alicante). Revista d'Arqueología de Ponent, 20: $127-144$.

Ripollés Adelantado, E. (1997): La Ereta del Castellar (Villafranca): avance a la revisión de un yacimiento del Bronce Valenciano. Archivo de Prehistoria Levantina, XXII: 157-178.

Ripollés Adelantado, E. (2000): Notas en torno a la tipología, cronología y origen de una punta de flecha de hueso localizada en el yacimiento de les Raboses (Albalat dels Tarongers, València): las puntas con doble hilera de aletas de la Edad del Bronce. Quaderns de Prehistòria i Arqueologia de Castelló, 21: 95-108.

Rodríguez Marcos, J. A.; Fernández Manzano, J. (eds.). (2012): Cogotas I: La cultura de la Edad del Bronce en la Península Ibérica. Universidad de Valladolid, Valladolid.

Rodríguez Tráver, J.A. Y Pérez Ballester, J. (2005): El poblamiento ibérico antiguo en el valle del río Canyoles. La Contestania ibérica, treinta años después, (L. Abad, F. Sala y I. Grau, eds.), Universidad de Alicante, Alicante: 211-225.

Rouillard, P.; Gailledrat, E.; Sala, F. (2007): L'etablissement protohistorique de La Fonteta (fin VIIIefin Vie siècle av.J.-C.), Casa de Velásquez, 96, Madrid.

Rouillard, P. (2010): La Fonteta/Rábita (Guardamar del Segura, Alicante): las excavaciones hispano-francesas, 1996-2001. Guardamar de Segura. Arqueología y museo. Museos, MARQ, Alicante: 80-89.

Ruíz Zapatero, G. (1978): Las penetraciones de Campos de Urnas en el País Valenciano. Cuadernos de Prehistoria y Arqueología de Castellón, 5: 243-255.

Ruíz Zapatero, G. (1985): Los campos de Urnas del noreste de la Península Ibérica. Universidad Complutense, Madrid.

Ruíz Zapatero, G. (2001a): El final de la Edad del Bronce en la Península Ibérica” ... Y acumularon tesoros. Mil años de historia en nuestras tierras, (M.S. Hernández, ed.), Caja de Ahorros del Mediterráneo, Alicante: 103-116.

Ruíz Zapatero, G. (2001b): Las comunidades del Bronce Final: enterramiento y sociedad en los Campos de Urnas. La Edad del Bronce, ¿primera Edad de Oro en España?: sociedad, economía e ideología, (M. Ruíz Gálvez, ed.), Ed. Crítica, Barcelona: 257-290.

Ruíz Zapatero, G. (2014): Los campos de Urnas. Protohistoria de la península Ibérica: del Neolítico a la romanización, (M. Almagro-Gorbea, ed.), Universidad de Burgos, Fundación Atapuerca, Burgos: 195216.

Schubart, H.; Pingel, V.; Arteaga, O. (2000): Fuente Álamo. Las excavaciones arqueológicas 1977-1991 en el poblado de la Edad del Bronce. Consejería de Cultura, Sevilla.

Simón García, J. L. (1987): Colecciones de la Edad del Bronce en el Museo Arqueológico Provincial de Alicante. Ingresos de 1967 a 1985 e Illeta dels Banyets de El Campello. Instituto de Estudios Juan GilAlbert, Vol. II, Alicante: 111-134. 
Simón García, J. L. (1997): La Illeta: asentamiento litoral en el Mediterráneo Occidental de la Edad del Bronce. La Illeta dels Banyets (El Campello, Alicante). Estudios de la Edad del Bronce y Época Ibérica, (M. Olcina, ed.), Museo Arqueológico Provincial de Alicante, Serie Mayor, 1, Alicante: 47-131.

Simón García, J. L. (1998): La metalurgia prehistórica valenciana. Serie de Trabajos Varios del Servicio de Investigación Prehistórica, 93. Diputación provincial, Valencia.

Soler DíAz, J. (2006): La ocupación prehistórica de la "Illeta dels Banyets" (El Campello, Alicante). Serie Mayor, 5, Museo Arqueológico de Alicante, Diputación Provincial de Alicante, Alicante.

Soler DíAz, J.A. (2009): Los confines del Argar en el registro arqueológico. Sobre la Illeta dels Banyets de El Campello, Alicante. En los confines del Argar. Una cultura de la Edad del Bronce en Alicante, (M.S. Hernández; J.A. Soler y J.A. López, eds.), MARQ, Alicante: 170-189.

Soler Díaz, J. A. (Ed.). (2012): Cova d'En Pardo: Arqueología en la Memoria: Excavaciones de M. Tarradell, V. Pascual y E. Llobregat (1961-1965), catálogo de materiales del Museo de Alcoy y estudios a partir de las campañas del MARQ (1993-2007) en la cavidad de Planes, Alicante. Fundación C. V. MARQ, Ayuntamiento de Alcoi.

Soler Díaz, J. A.; Ferrer, C.; González, P.; Belmonte, D.; López D.; Iborra, P.; Closquell, B.; Roca De Togores, C.; Chiarri, J.; Rodes, F.; Martí, J. B. (1999): Uso funerario al final de la Edad del Bronce de la Cova d'En Pardo, Planes, Alicante. Una perspectiva pluridisciplinar. Recerques del Museu d'Alcoi, 8: 111-178.

Soler García, J. A. (1987): Excavaciones arqueológicas en el Cabezo Redondo. Instituto de Cultura Juan Gil-Albert, Alicante.

Soriano Boj, S.; Jover Maestre, F.J.; López Seguí, E. (2012): Sobre la fase Orientalizante en las tierras meridionales valencianas: el yacimiento de Casa Secà (Elche) y la dinámica del poblamiento en el Sinus Ilicitanus. Saguntum, 44: 77-97. doi: 10.7203/SAGVNTVM.

Tarradell Mateu, M. (1963): El País Valenciano del Neolítico a la Iberización. Ensayo de síntesis, Valencia.

Tarradell Mateu, M. (1969): La cultura del Bronce Valenciano. Nuevo ensayo de aproximación. Papeles del Laboratorio de Arqueología de Valencia, 6:7-30.

Torres Ortíz, M. (2008): Dataciones del C-14 del Bronce Final del Sureste. Qurénima, El Bronce Final del Sudeste de la península Ibérica, (A. J. Lorrio Alvarado, ed.), Apéndice IV, Bibliotheca Archaeologica Hipana, 27, Madrid: 539-544.

Trelis Martí, J. (1992): Excavaciones en el yacimiento de la Edad del Bronce de Mas de Corral (Alcoi, Alicante). Recerques del Museu d'Alcoi, 1: 85-89.

Trelis Martí, J. (1995): Aportaciones al conocimiento de la metalurgia del Bronce Final en el sureste peninsular: el conjunto de moldes del Bosch (Crevillente, Alicante). Actas del XXIII Congreso Nacional de Arqueología, vol. I, Elche: 185-190.

Trelis Martí, J.; Molina Mas, F. A.; Esquembre Bebia, M. A.; Ortega Pérez, J. R. (2004): El Bronce Tardío e inicios del Bronce Final en el Botx (Crevillent, Alicante): Nuevos hallazgos procedentes de excavaciones de salvamento. La Edad del Bronce en tierras valencianas y zonas limitrofes, (L. Hernández y M.S. Hernández, eds.), Instituto de Cultura Juan Gil-Albert, Ayuntamiento de Villena, Villena: 319-324.

Vives-Ferrándiz, J. (2005): Negociando encuentros. Situaciones coloniales e intercambios en la costa oriental de la península Ibérica (ss. VIII-VI a.C.). Barcelona.

Vizcaíno, D. (Ed.). (2007): Paisaje y arqueología en la Sierra de la Menarella. Estudios previos del Plan Eólico Valenciano. Zona II: Refoies y Todolella. Generalitat Valenciana, Valencia. 